\title{
Urbanization can benefit agricultural production with large-scale farming in China
}

\author{
Sitong Wang ${ }^{1,2,10}$, Xuemei Bai $\mathbb{1}^{3,10}$, Xiaoling Zhang ${ }^{4,5,10}$, Stefan Reis $\mathbb{1}^{6,7}$, Deli Chen $\mathbb{(}^{8}$, \\ Jianming Xu ${ }^{1,9}$ and Baojing Gu ${ }^{1}{ }^{1,9 凶}$
}

\begin{abstract}
Urbanization has often been considered a threat to food security since it is likely to reduce the availability of croplands. Using spatial statistics and scenario analysis, we show that an increase in China's urbanization level from $56 \%$ in 2015 to $80 \%$ in 2050 would actually release 5.8 million hectares of rural land for agricultural production-equivalent to $4.1 \%$ of China's total cropland area in 2015. Even considering the relatively lower land fertility of these new croplands, crop production in 2050 would still be 3.1-4.2\% higher than in 2015. In addition, cropland fragmentation could be reduced with rural land release and a decrease in rural population, benefiting large-scale farming and environmental protection. To ensure this, it is necessary to adopt an integrated urban-rural development model, with reclamation of lands previously used as residential lots. These insights into the urbanization and food security debate have important policy implications for global regions undergoing rapid urbanization.
\end{abstract}

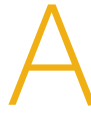
$s$ the world population becomes increasingly urban, there is growing concern that urbanization is taking away valuable cropland around the world, thus presenting a major risk to food security ${ }^{1,2}$. This was supported by previous studies, which showed, for instance, that global urban expansion would result in a $1.8-2.4 \%$ loss of global croplands by 2030 , leading to a $3-4 \%$ reduction of worldwide crop production-the majority occurring in Asia and Africa ${ }^{3}$, where a large proportion of the population still live in rural areas. Urbanization is therefore usually viewed by policymakers, scholars and the general public alike as a major global threat to cropland availability and food security ${ }^{4,5}$, and policies have been implemented to restrict the occupation of cropland by urban expansion $^{4,5}$

China, the most populous country in the world, has been undergoing rapid urbanization for four decades ${ }^{6}$. The share of urban population to total population is growing at a rate of $1 \%$ per year, implying an approximate $80-90 \%$ urbanization level by 2050 if this pace continues ${ }^{7,8}$. For this to happen, the population in urban areas would increase approximately 330-470 million as a result of migration or natural growth, which is close to the total population of the European Union (Supplementary Table 1) ${ }^{7}$. To accommodate these new residents, cities will need to expand and occupy surrounding lands, including existing and potential croplands. Recent studies of urbanization and food security have highlighted the potential competition for land use between agricultural use and urban expansion $^{3,9-13}$, estimating a $5.3 \%$ loss of cropland and $8.7 \%$ decrease in crop production in China by $2030^{3}$. However, it is salutary to note that, in 2015, although the country's rural population was $20 \%$ less than its urban population, the built-up area of human settlement was $160 \%$ more in rural areas (Supplementary Tables 1 and 2 and Fig. 1a,b). Thus, urbanization has the potential to release lands for crop production, which is largely ignored in the current urbanization-agricultural production debate, and the quantity involved and its impact on food security are, as yet, unclear.

In response, we analysed and quantified the potential amount of cropland release from China's urbanization between 2015 and 2030 (that is, the anticipated peak population level) and 2050 (that is, the projected peak urbanization level) based on 2000-2015 empirical data for cropland and built-up area changes in both urban and rural areas. Using spatial statistics and scenario analysis, we identified the rural lands that are more suitable for being reclaimed as cropland and the peripheral urban lands that will need to be occupied for urban expansion (Fig. 5). This information was then combined with an analysis of the land fertility and farm size in each of the $>2,800$ counties in China to estimate the impact of urban expansion and rural land reclamation on crop production, food security and the environmental sustainability of agriculture under future scenarios.

\section{Release of croplands}

China is a prime example of urbanization accompanied by a continued increase in rural built-up land area (Fig. 1). While its urbanization level increased from 36-56\% between 2000 and 2015, leading to a population decrease of 200 million people in rural areas, the rural built-up area increased by 0.5 million hectares (Mha) (Fig. 1a) and the cropland area decreased by $1.6 \mathrm{Mha}$ (Supplementary Table 3). The lack of a social security network in cities means that migrating workers are unwilling to abandon their rural homestead and would prefer to use the money they earn from urban areas to build new houses in rural areas. Such double-dipping land waste in rural China, which is an unintended consequence of the Hukou system (mainland China's system of household registration, which separates urban and rural residents), provides great potential for

\footnotetext{
${ }^{1}$ College of Environmental and Resource Sciences, Zhejiang University, Hangzhou, People's Republic of China. ${ }^{2}$ Policy Simulation Laboratory, Zhejiang University, Hangzhou, People's Republic of China. ${ }^{3}$ Fenner School of Environment and Society, Australian National University, Canberra, Australian Capital Territory, Australia. ${ }^{4}$ Department of Public Policy, City University of Hong Kong, Hong Kong, People's Republic of China. ${ }^{5}$ Shenzhen Research Institute, City University of Hong Kong, Shenzhen, People's Republic of China. ${ }^{6}$ UK Centre for Ecology \& Hydrology, Penicuik, UK. ${ }^{7}$ European Centre for Environment and Human Health, University of Exeter Medical School, Truro, UK. ${ }^{8}$ School of Agriculture and Food, The University of Melbourne, Melbourne, Victoria, Australia. ${ }^{~}$ Zhejiang Provincial Key Laboratory of Agricultural Resources and Environment, Zhejiang University, Hangzhou, People's Republic of China. ${ }^{10}$ These authors contributed equally: Sitong Wang, Xuemei Bai, Xiaoling Zhang. $\varpi_{e}-m a i l:$ bjgu@zju.edu.cn
} 

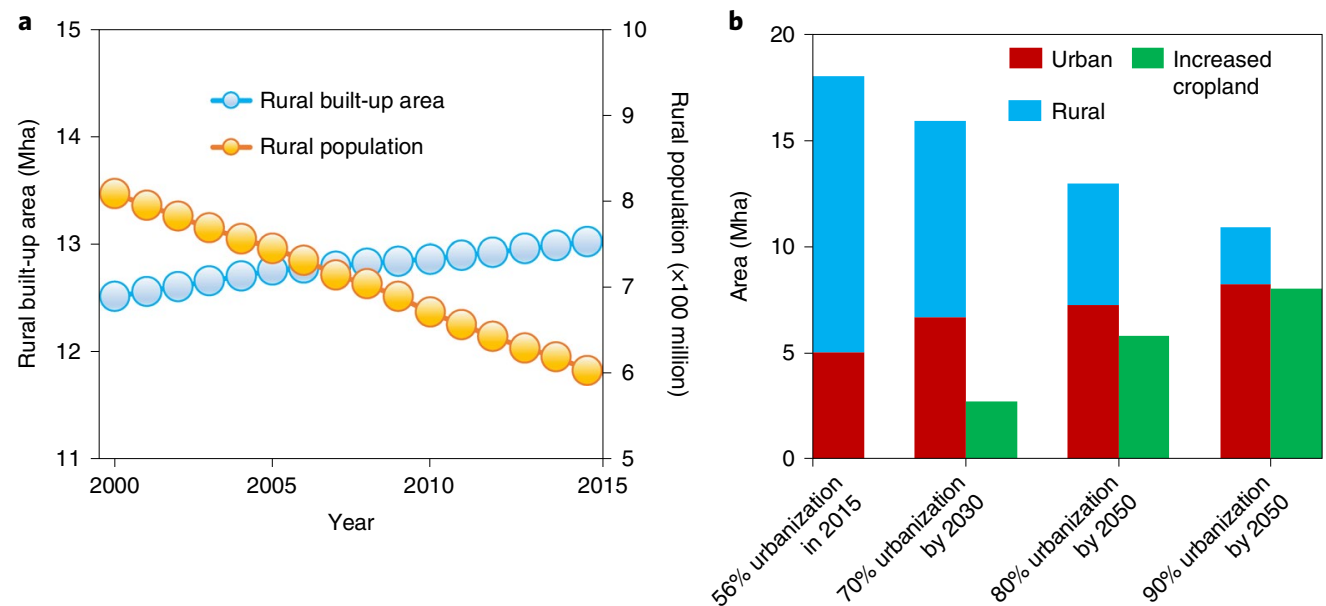

Fig. 1 Changes in urban, rural and cropland areas and rural population. a, Changes in the rural built-up area (left yaxis) and population (right yaxis) from 2000-2015. b. Changes in urban, rural and cropland areas under various scenarios. Urban and rural refer to built-up lands occupied by people living in urban and rural built-up areas, respectively.

releasing rural land for crop production through better management of urban-rural integration.

With urbanization, more rural land occupied for residential use can be released than urban land can be used for expansion. For example, if the urbanization level were to reach $70 \%$ by 2030 , rural land occupation would decrease by 3.8 Mha while urban land occupation would only increase by 1.7 Mha (Fig. 1). Approximately 0.7 out of the 1.7 Mha would stem from non-croplands ( 0.2 Mha rural lands and 0.5 Mha natural lands), suggesting that about 2.7 Mha of additional land could be reclaimed for crop production. By 2050, it is estimated that the urbanization level could further increase to $80 \%{ }^{3}$, or even $90 \%$ if the existing urbanization rate continues. In the following sections, we discuss the results assuming that the urbanization level will reach $80 \%$ in 2050 , which is based on the projections of the United Nations' World Urbanization Prospects? To support the analysis, we also include the results assuming an urbanization level of $90 \%$, which assumes that the current rate of urbanization in China would continue to 2050 (Extended Data Figs. 2, 7 and 8 and Supplementary Tables 1-4 and 6).

The total population is projected to decrease by around $76 \mathrm{mil}-$ lion in 2050 compared with the peak level expected to occur around 2030. These figures indicate that, compared with 2030, the 2050 total urban land occupation would need to have increased by only 0.6 Mha while rural land occupation could decrease by as much as 3.5 Mha with the urbanization level increasing to $80 \%$. Therefore, the net land area released for croplands could amount to $5.8 \mathrm{Mha}$ by 2050 (Fig. 1b and Supplementary Table 2), accounting for $4.1 \%$ of China's total cropland area in 2015. Considering the changes of future urban population density, this net land area release will vary from 4.3-6.0 Mha under future low and high urban density scenarios (see Methods for details). Approximately $0.6 \mathrm{Mha}$ of natural lands surrounding cities would be occupied in 2050, which would enable the release of rural lands for agriculture use.

Projecting forward, with no rural lands reclaimed, the total cropland area would decrease by 1.3 Mha between 2015 and 2050, driven primarily by urbanization (Extended Data Fig. 3b), mainly in regions where urban expansion would occur (Fig. 2). However, if we account for reclaiming rural land areas, a substantial increase of cropland areas can be anticipated from 2015-2030 (+2.7 Mha) and from 2015-2050 (+5.8 Mha) in the majority of counties (except a number of large metropolitan areas, such as Beijing and Shanghai; Extended Data Fig. 3c). Urban expansion in these metropolitan regions would therefore occupy more cropland than would be released, largely due to cross-region migration (Extended Data Fig. 3d). For instance, the decrease in large rural built-up areas in the North China Plain (NCP) would accompany the migration of their rural population to metropolitan regions, where additional cropland will need to be converted to residential areas. Thus, the released lands would mainly be located in the NCP, Middle and Lower Yangtze River Plain (MLYRP) and Northeast China Plain, where the rural population typically occupies a large area of flat rural lands that are well suited to be reclaimed for crop production (Fig. 2 and Extended Data Fig. 1).

\section{Increase in crop production via increased cropland area}

Our results show that crop production increases with urbanization, considering the changes of both cropland area and crop yield. Crop yield is influenced by soil fertility, as well as other factors such as farming technologies. We estimated the changes in soil fertility, as measured by the amount of soil organic carbon (SOC). Based on empirical data of crop yield between 2000 and 2015, we demonstrate the limited impact of estimated changes in SOC on crop yield. Even if urban expansion occupied fertile croplands, the average level of SOC would hardly change with urbanization. From 2000-2015, there was an overall $0.2 \%$ decrease in SOC content at the national scale, with both regional increases and decreases accompanying widespread urbanization (Extended Data Fig. 4a). Projecting forward from 2015-2050, if no rural built-up lands previously used as residential lots were reclaimed, the total cropland area would decrease due to urban expansion, with a slight increase in overall SOC nationally (Extended Data Fig. 4b). With rural land being reclaimed, the average SOC would decrease by approximately $0.03 \%$ by 2030 (Extended Data Fig. 4c) and then would further decrease by 0.14\% by 2050 (Extended Data Fig. 4d).

Compared with the minute changes in SOC, crop yield has changed substantially, with an increase of 30\% from 2000-2015 due to the increased uptake of new farming technologies, despite the net loss in cropland area as a result of urban expansion. On a spatial scale, a high crop yield occurs in the NCP and MLYRP regions (Supplementary Fig. 14) ${ }^{14}$, which are also preferential regions for rural reclamation due to their large rural populations. More favourable natural conditions in the plains and a moderate climate make these regions the so-called bread basket of China. Thus, even urbanization occupying fertile croplands in eastern 


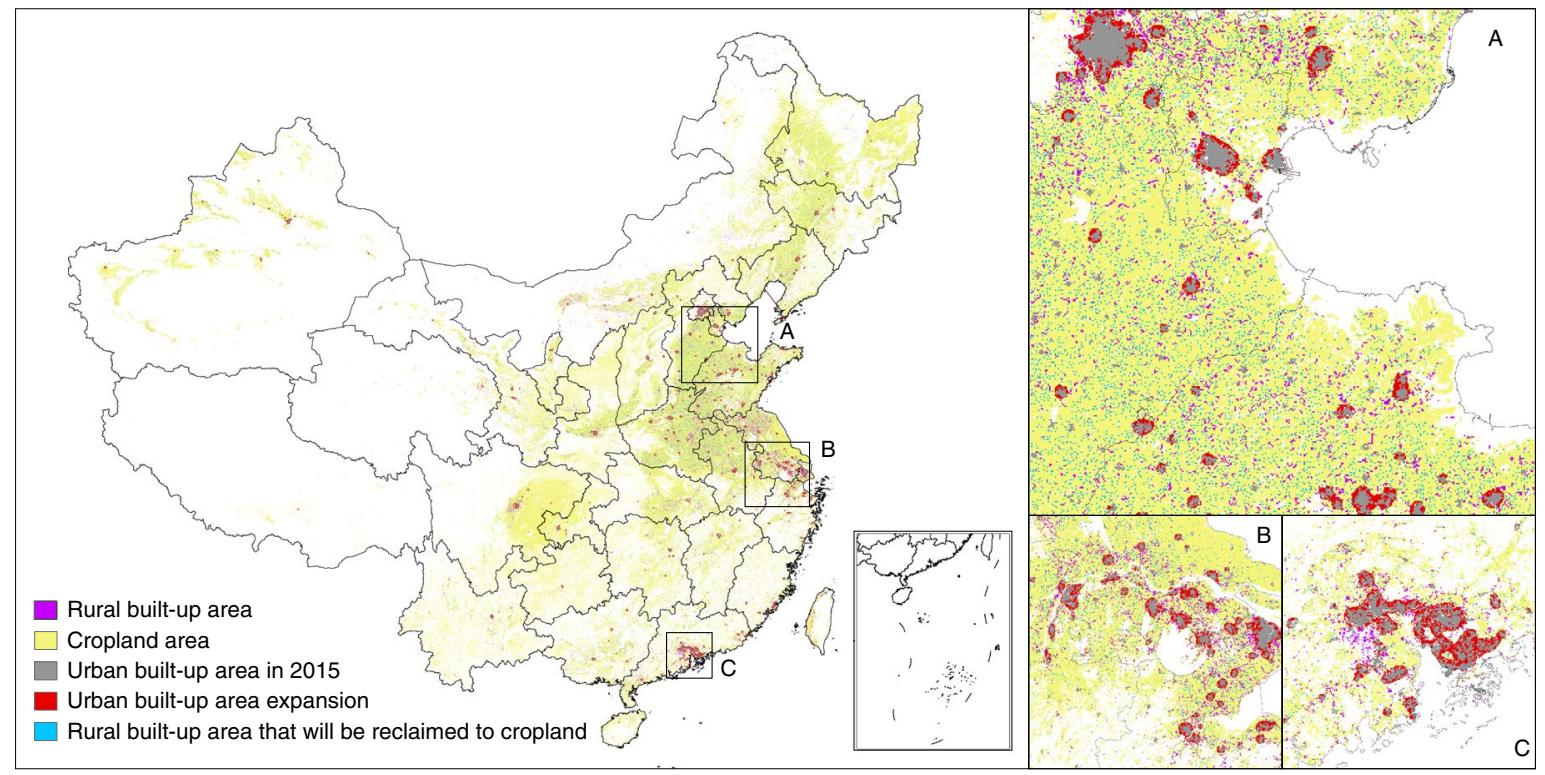

Fig. 2 Spatial changes in land use with an urbanization level of $\mathbf{8 0 \%}$ in $\mathbf{2 0 5 0 . ~ F r o m ~ 2 0 1 5 - 2 0 5 0 , ~ n e w ~ r e l e a s e d ~ c r o p l a n d s ~ w o u l d ~ b e ~ c o n c e n t r a t e d ~ i n ~ t h e ~}$ NCP (A), MLYRP and Northeast China Plain, while the most intensive urban expansion areas would be the Beijing-Tianjin-Hebei region, Yangtze River Delta (B) and Pearl River Delta (C). Maps showing the distribution of land use changes at urbanization levels of 56, 70 and $90 \%$ (by 2015,2030 and 2050, respectively) are provided in Extended Data Figs. 1 and 2. The base map was applied without endorsement using data from the Database of Global Administrative Areas (GADM; https://gadm.org/).

coastal China and rural land reclamation in the NCP and MLYRP can lead to an increase in the average crop yield at a national scale. If the crop yield of each land remained at the 2015 level and the change was only influenced by the land being lost or reclaimed, the projected national average crop yield would increase by $0.5 \%$ from $2015-2030$. This value would further increase to $0.9 \%$ by 2050 with an urbanization level of $80 \%$ (Extended Data Fig. 5). Meanwhile, the crop yield might further increase by $20-40 \%$ in 2050 (relative to 2015) because crop varieties and agricultural management practices are evolving with the increase in technological and economic development accompanying urbanization (Supplementary Table 16) ${ }^{15}$. This effect will be much larger than the increase in agricultural production derived from changes of croplands area, which may reduce the incentive for rural build-up land reclamation. Nevertheless, it is difficult to accurately predict such a long-term change of crop yield; thus, we use the 2015 yield as a robust basis for estimating the effect of urbanization on crop production.

We estimated the changes of crop production, taking into account both the changes of quality (that is, $\mathrm{SOC}^{16,17}$ and crop yield in 2015) and quantity of cropland (that is, area). As discussed above, there would be no notable changes in SOC with urbanization; thus, the spatial variation of crop production would mainly be determined by the changes of cropland area and crop yield. From 2000-2015, crop production decreased in 1,875 counties and increased in 318 counties, leading to an overall 1.1\% decrease on a national scale (Fig. 3a). From 2015-2050, without rural land being reclaimed, crop production was projected to decrease in 449 counties (Fig. 3b), mainly located in regions of urban expansion, with a $0.7 \%$ decrease in total crop production nationally. However, reclaiming rural land would enable total crop production to actually increase by 1.4 and $3.1 \%$ in 2030 and 2050, respectively, compared with 2015 (Fig. 3c,d).

Assuming the yield in 2015 could remain the same in the future, our findings indicate that total crop production would increase by $2.0 \%$ in 2030 and could further increase to $4.2 \%$ in 2050 (Fig. 3e,f). These estimates are higher than the results derived from projections based on SOC, suggesting that urbanization could not only free lands, but might also increase crop yield through better agricultural management such as irrigation, fertilizer and labour training. These increases would mainly occur in the plains, such as the NCP and MLYRP, similar to the increase in SOC-predicted crop production, suggesting that, in both cases, changes in cropland area dominate future changes in crop production with urbanization (with changes in crop yield further contributing to the increase).

\section{Increase in farm size with rural consolidation}

In addition to the increase in crop production, we found that the average farm size may change with the increase in cropland area per rural resident. While farm size (cropland area managed by each rural household) and cropland area per rural resident are not the same, the land tenure system in China tends to adopt equal allocations of cropland to rural households ${ }^{18}$. Therefore, the resulting farm size is similar to the per-household availability of land in China. Urbanization increases the total cropland area and decreases the rural population (Extended Data Fig. 6), resulting in a higher per-capita cropland area of rural residents and, therefore, increased farm size. This is important, as a labour-intensive small farm size is often considered a bottleneck for introducing modern agricultural practices $^{18}$. From 2000-2015, the per-capita cropland area of rural residents increased in 1,256 counties, mainly located in regions where cropland area increased (including Northwest and Northeast China) or regions with a decrease in the rural population (including Southeast China, Guangdong, Shandong and Jiangsu). In contrast, a substantial decrease in per-capita cropland area occurred in 883 counties because of their decreased cropland areas (Fig. 4a). At the national scale, the rural residents' per-capita cropland area increased by $4.5 \%$ from $2000-2015$.

From 2015-2050, assuming no rural land was reclaimed, we still found a projected rural residents' per-capita cropland area increase of nearly $69 \%$; although the cropland area would decrease by $1.0 \%$, the rural population would decrease by $40.6 \%$ (Fig. 4b). Meanwhile, 79 counties would no longer have any rural residents, suggesting the potential for extensive cross-county land consolidation and management. In contrast, if rural land was reclaimed, the total cropland 
a

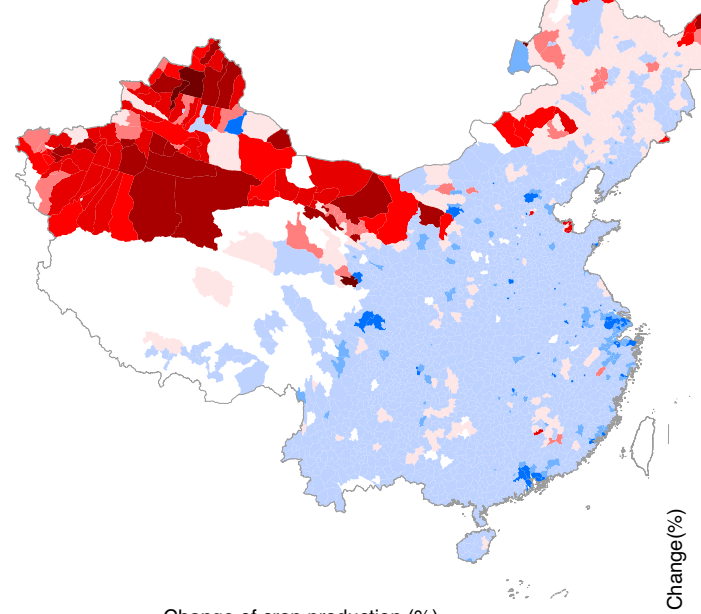

b

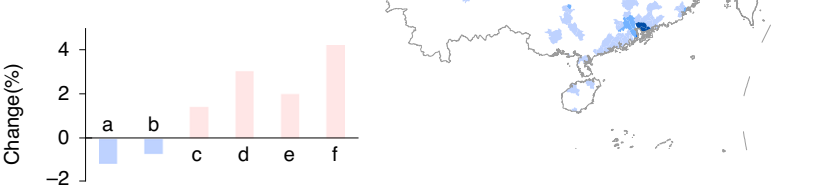

d

c
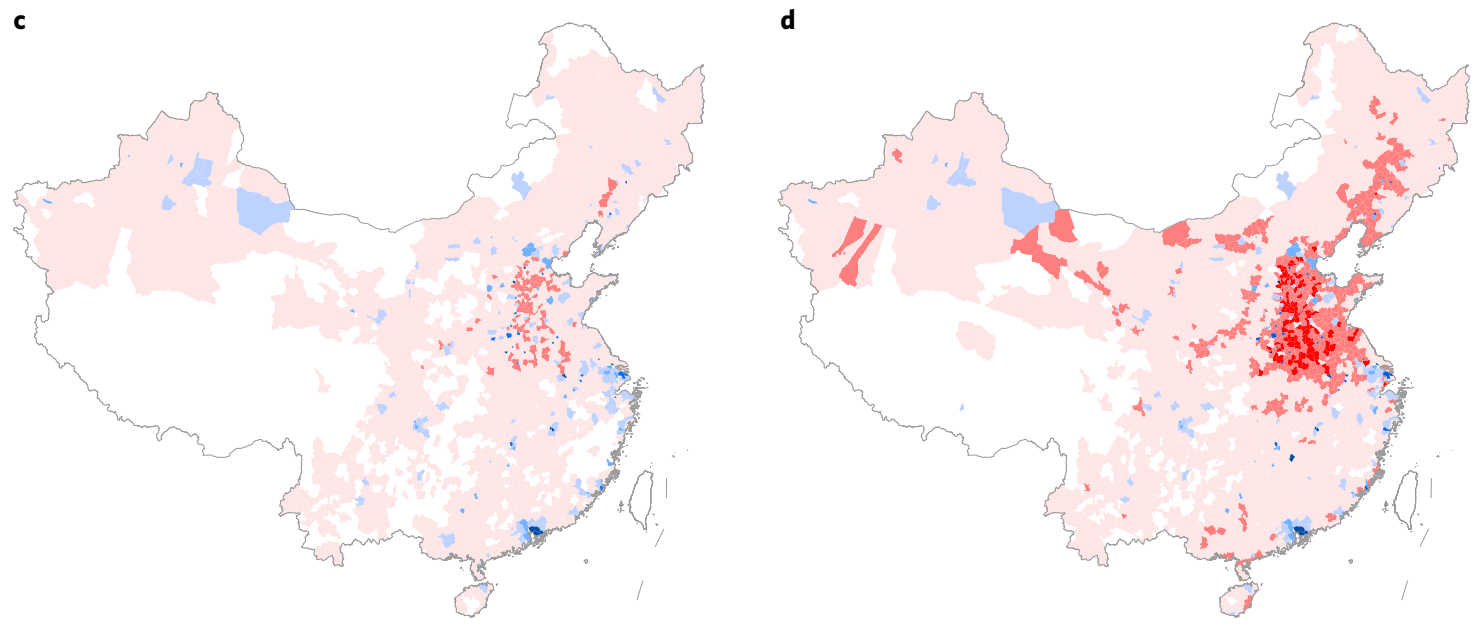

e

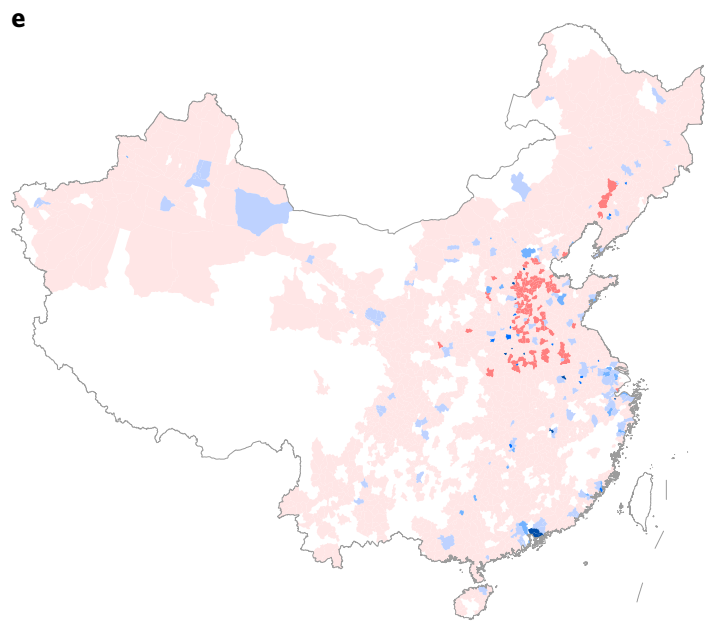

,

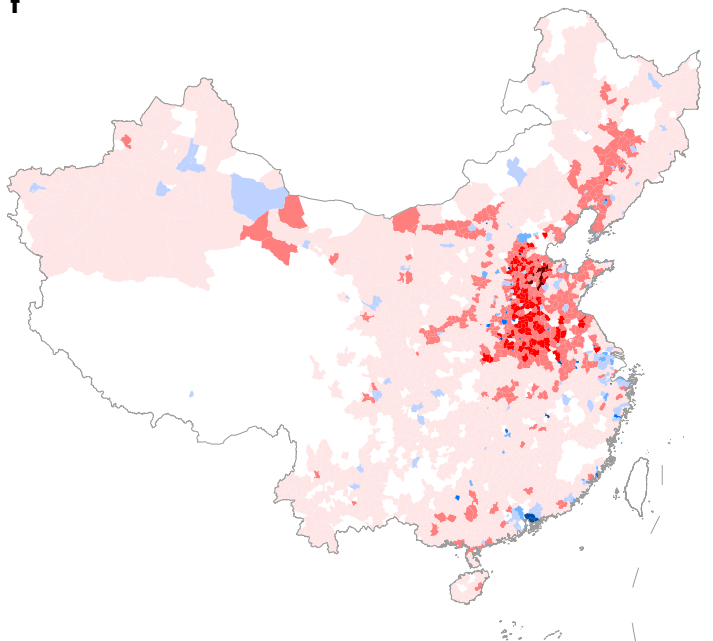

Fig. 3 | Changes in crop production at the county level. a-f, County-level changes in crop production from 2000-2015 (a), from urbanization level 56\% (2015) to urbanization level 80\% (2050) without rural land being reclaimed (b), from urbanization level 56\% (2015) to urbanization level 70\% (2030) with rural land being reclaimed, as predicted by SOC (c), from urbanization level 56\% (2015) to urbanization level $80 \%$ (2050) with rural land being reclaimed, as predicted by SOC (d), from urbanization level 56\% (2015) to urbanization level 70\% (2030) with rural land being reclaimed, as predicted from the yield of 2015 (e) and from urbanization level 56\% (2015) to urbanization level 80\% (2050) with rural land being reclaimed, as predicted from the yield of 2015 (f). The inset bar chart shows the overall changes for 2000-2015 and each scenario in the future for China as a whole (Supplementary Table 6). The base map was applied without endorsement using data from the GADM (https://gadm.org/). 

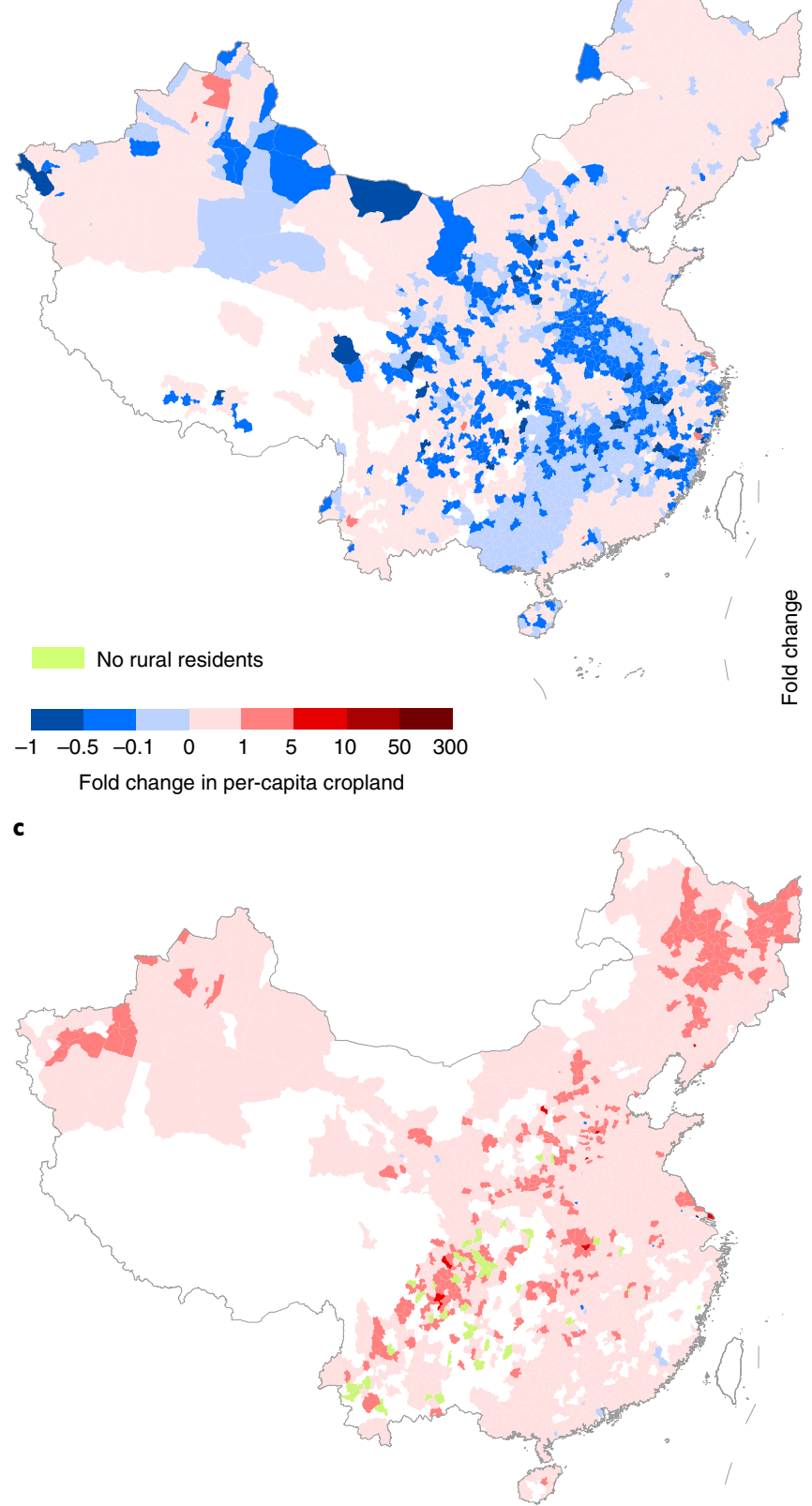

b

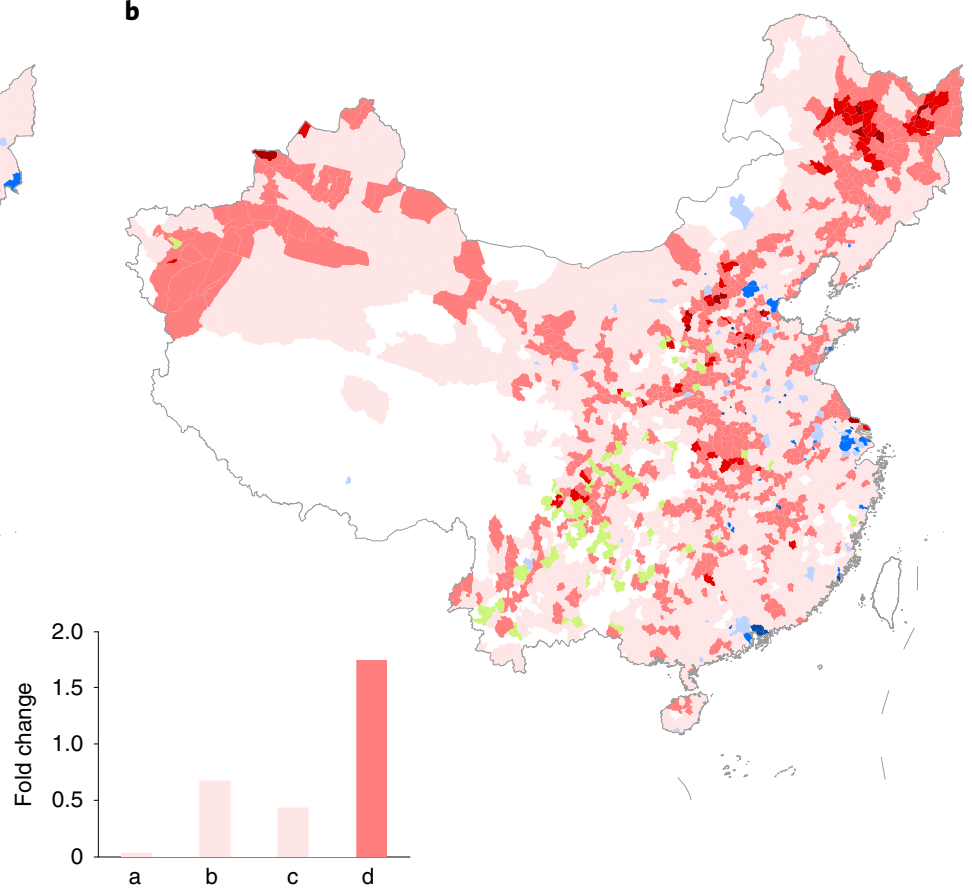

d

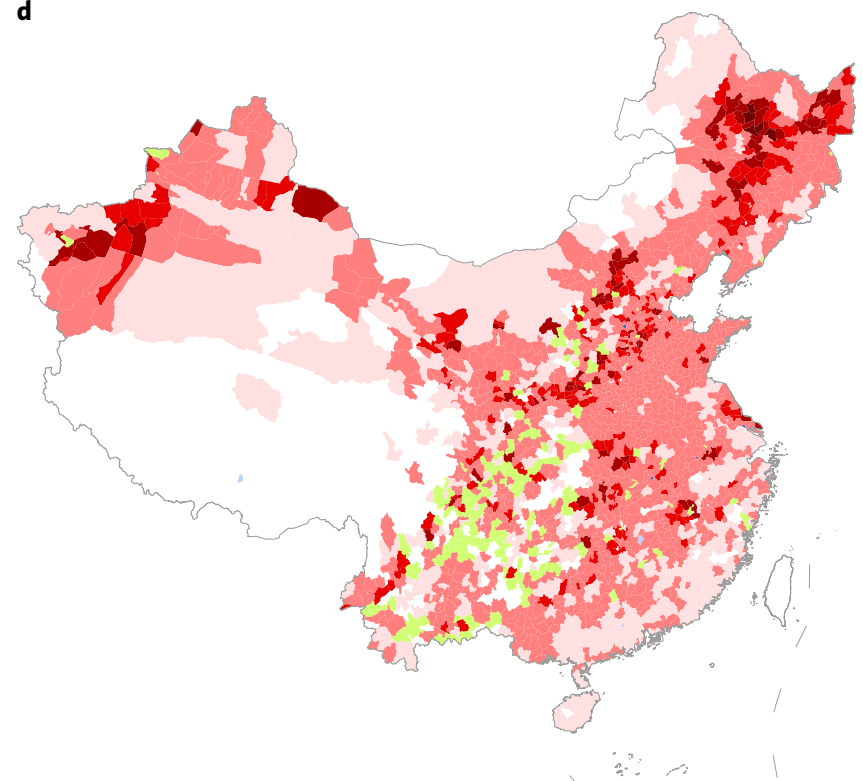

Fig. 4 | Changes in per-capita cropland of rural residents at the county level. a-d, Changes in cropland from 2000-2015 (a), from urbanization level 56\% (2015) to urbanization level 80\% (2050) without rural land being reclaimed (b), from urbanization level 56\% (2015) to urbanization level 70\% (2030) with rural land being reclaimed, as predicted by SOC (c) and from urbanization level 56\% (2015) to urbanization level 80\% (2050) with rural land being reclaimed, as predicted by SOC (d). The inset bar chart shows the overall changes for 2000-2015 and each scenario in the future for China as a whole (Supplementary Table 7). The base map was applied without endorsement using data from the GADM (https://gadm.org/).

area would increase by $1.9 \%$ and the rural population would decrease by $28.5 \%$, resulting in a $45 \%$ increase in rural residents' per-capita cropland area in 2030 (Fig. 4c). Furthermore, should urbanization continue to $80 \%$ by 2050 , the total cropland area would increase by $4.1 \%$ and the rural population would decrease by $61.5 \%$, leading to a twofold increase in the rural residents' per-capita cropland area. In this case, the number of counties without rural residents would increase to 168 , suggesting that cross-county land consolidation would become critical for food security on a national scale in the context of cross-regional migration (Fig. 4d).
There would be changes in the quantity and quality of the labour force, especially in rural areas, where there are labour shortages and the population is ageing ${ }^{19}$. A higher urbanization ratio could also be achieved through the natural increase of urban populations and continued shrinking of the rural population over the next couple of decades due to ageing. This is becoming increasingly evident (around 80 villages are abandoned in China every day due to shrinking of the rural population through ageing ${ }^{7}$ ) and would also provide opportunities for an increase in large-scale farming, mechanization and modernization of agriculture-thereby 

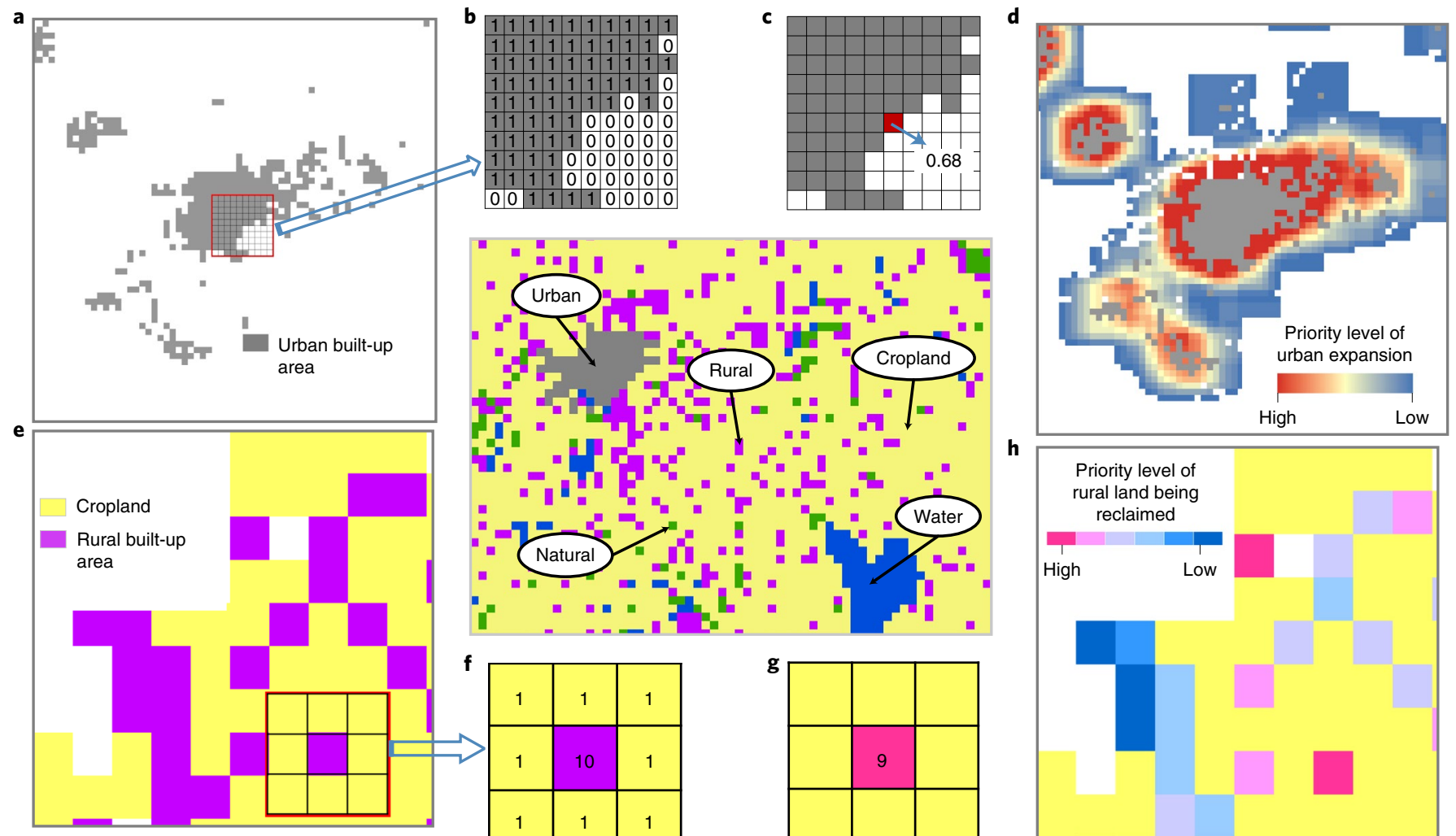

h

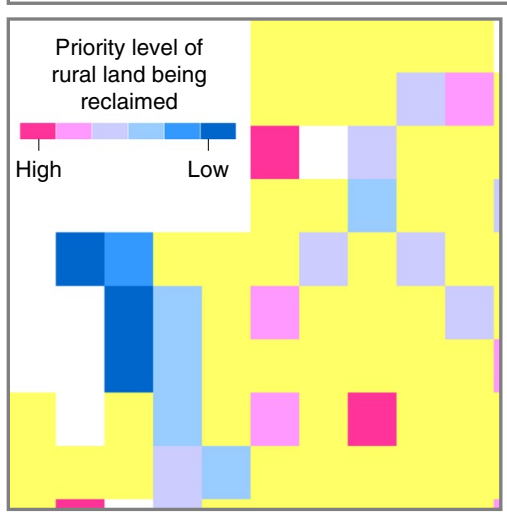

Fig. 5 | Methods for predicting urban and rural land use change. a, An urban built-up area in 2015. b, Pick up a square with $10 \times 10$ grids, set the value of urban land to 1 and set the value of all other land uses to 0 . c, Count all of the values in the square and calculate the priority level for the central grid using equation (1). d, Example of the priority level of urban expansion. e, An example of cropland and rural built-up area distribution in 2015. $\mathbf{f}$, Pick up a square with $3 \times 3$ grids, set the value of cropland to 1 and set the value of rural built-up area to $10 . \mathbf{g}$, Count all of the values in the square and calculate the priority level for the central grid using equation (2). $\mathbf{h}$, Example of the priority level of rural land being reclaimed. The inset plot shows a typical case of regional land use. The yellow background denotes croplands; the grey grids denote urban lands; and the scattered purple grids denote rural lands.

benefiting the improvement of farming productivity. Recently, there has been an increase in farming service rental activities (for example, for sowing, fertilization and harvesting in rural areas) ${ }^{20}$. Many ageing farmers no longer work by themselves but use service rental to manage their farming land, which leads to an increase in labour productivity. Alternatively, ageing farmers transfer land areas to large landholders, which fundamentally promotes the development of large-scale farming ${ }^{21}$.

\section{Increase in agricultural productivity}

The growth in farm size has great implications for agricultural production, especially for smallholder farmers. In China, the Household Contract Responsibility System (HCRS) allocates croplands to all rural residents evenly in each village, considering both the quantity and quality of their lands ${ }^{21}$. This is a major driver of cropland fragmentation in China, hindering large-scale agricultural production. The current average farm size of rural households is only $0.5 \mathrm{ha}^{18}$, but this value could reach 1.35 ha with urbanization (Fig. 4). Thus, with the release of cropland coupled with rural population reduction, agricultural production is likely to become increasingly dominated by large-scale farming. This trend has occurred in many high-income countries, with the convergence of rapid urbanization and larger farm size creating new demands for modern agricultural practice (Supplementary Figs. 12 and 13 ) $^{18}$. As a critical pathway to the modernization and sustainable development of agriculture, large-scale farming has a positive impact on the farmers' net profits and economic, technical and labour efficiency ${ }^{22-27}$, as well as environmental protection through the decreased use of fertilizers and pesticides ${ }^{18,21,28}$. Existing studies have also found that, with the increase of farm size, farmers tend to use more fixed inputs (for example, machinery and knowledge) compared with non-fixed inputs (for example, fertilizers and pesticides) to increase crop yields ${ }^{22}$. Fixed inputs could increase the efficiency of fertilizer and pesticide use and thus reduce their losses to the environment, which in turn contributes to the environmental sustainability of agricultural production.

Even if the aggregate soil fertility of reclaimed croplands were lower than the croplands occupied by urban expansion (Extended Data Fig. 4), the crop yield could still increase with more productive agricultural management during urbanization. Regions with favourable natural conditions for farming before urbanization occurred have more rural populations (for example, the NCP and MLYRP in China). Regardless of cropland quality being low at the beginning of rural land reclamation, it is likely to improve with agricultural management in the long term. High fertilizer use intensity is typically concentrated in highly urbanized regions, which are also more technologically and economically advanced ${ }^{15}$. Therefore, in addition to the more productive agricultural management of larger farms, land release with urbanization could potentially improve cropland quality, both of which would lead to higher crop yield and less pollution. With productivity growth resulting from technological progress, crop yield would further increase and result in higher crop production ${ }^{29}$ - a scenario that is likely to become more viable with urbanization and large-scale agricultural production ${ }^{18}$. As mentioned above, crop yield has increased by $30 \%$ from $2000-2015$ due to the increased uptake of new technologies ${ }^{14,30}$; therefore, from 
multiple perspectives, such as agricultural inputs, nutrient losses and crop yields, we can expect that urbanization has the potential to enhance agricultural productivity in line with reducing its environmental impact.

\section{Feasibility of rural land release}

Although urbanization can potentially improve crop production by releasing rural land and increasing yield, it relies on the feasibility and success of rural built-up land being reclaimed for crop production and hosting more efficient technologies and management practices ${ }^{15}$. The option to release rural land is constrained in high-income countries where urbanization is nearly completed ${ }^{3}$ and much of the cropland that exists already is under large-scale and intensive production ${ }^{18}$. Urban expansion with further population growth in these regions is more likely to lead to direct cropland loss and there is less potential for rural land release. However, situations differ in developing economies with a lower urbanization level and limited intensification, where rural-to-urban migration is a common phenomenon and urbanization does not necessarily involve a net cropland loss. Urban development accompanied by rural-to-urban migrants settling in and being accepted and integrated into cities eliminates the need for migrant workers to keep and even expand their rural housing, which will help to optimize the allocation of land resources and labour, as well as maximize land use efficiency in urban and rural areas.

Land reclamation incurs economic costs. Based on existing cases, we found the current cost of rural reclamation to be around US $\$ 23,000 \mathrm{ha}^{-1}$, with large variation from US\$3,000-50,000 ha ${ }^{-1}$ across China (Extended Data Fig. 9). Although this one-time investment is high, these new croplands can be used in the following decades or even centuries, lowering the annual cost of reclamation. Meanwhile, as croplands are state owned in China, these reclamation costs are covered by governments, which reduces the burden on farmers running these new farms. The majority of cases are from Northeastern and Northwestern China, the NCP and the MLYRP, where large-scale farming is already prevalent (Extended Data Fig. 10). That the total area of rural reclamation has reached over 40,000 ha during the past decade ${ }^{31}$ suggests that it is not only feasible but also happening in practice, especially in regions with the potential for large-scale farms. Furthermore, from the perspective of national strategies, reclamation is related to urban development and food security, both of which are important livelihood issues. It is therefore not a straightforward question of cost-effectiveness. For instance, many countries, including China, may choose to maintain food security regardless of the cost, especially when experiencing international trade disputes, instability and a possible food crisis under the COVID-19 pandemic ${ }^{32}$. These suggest added incentives for the government to protect cropland irrespective of cost.

It is critical to consider the livelihood and wellbeing of smallholder farmers who may lose their land in the process of urbanization. According to a survey in a rural area of Shanghai, the income of most farmers tends to increase once they lose their land $^{33}$. It was found that more job opportunities could be secured in high-income regions (such as Shanghai) in China, while farmers in the low-income regions who have a low non-agricultural capability of earning a living may be unable to maintain a sustainable livelihood. In this context, there are both opportunities and risks involved in replacing small-scale farms with larger-scale farms and modern agricultural production. However, irrespective of highor low-income regions, agricultural income from a small area of cropland ( $<0.5$ ha per household) is no longer sufficient (normally $<20 \%$ of their total income) to feed a family. Although governments provide social welfare to such low-income people, more policy arrangements should further increase their non-agricultural incomes to facilitate land release for development. In addition, the value of local and traditional knowledge held by smallholder farmers is increasingly recognized ${ }^{34}$. Policymakers need to carefully consider these factors to harness the potential benefits of urbanization for enhancing agricultural sustainability.

\section{Policy implications}

To stay within the red line of arable cropland (that is, cropland area should be $>120 \mathrm{Mha}$ ) and secure food security for its population of 1.4 billion people, China's central government has enacted several regulations, including the cropland requisition-compensation balance and increasing versus decreasing the balance of urban-rural construction land ${ }^{35}$. The implementation of these regulations has helped to guarantee food security to some extent, but has also created unintended outcomes, such as the indirect loss of natural lands, fragmentation of croplands and limitations on the release of rural land (Supplementary Figs. 1 and 9-11 and Supplementary Table 14) ${ }^{1}$. Our results show that urbanization has the potential to release cropland through reclaimed rural lands. To release cropland, a comprehensive coordinated institutional reform of man-land linkage should help to reduce the negative externalities involved. The Hukou system, the HCRS and their conflict are the fundamental institutions behind the mismatch between population density and land potential. The Hukou system has reduced land use efficiency in rural areas, especially when farmers are working in the urban area with idle land left in the countryside. While HCRS protects the basic right of rural residents, it also results in cropland fragmentation and restricts the development of large-scale modern agriculture.

To date, reforms of the Hukou system and HCRS have been piloted in some Chinese cities and counties ${ }^{36}$ so that farmers can exchange their rural settlements and croplands for being eligible to access public services such as medical and social insurance resources in urban areas. Meanwhile, farmers who voluntarily withdraw from residential land need adequate compensation and incentives. For abandoned and fragmented cropland, the separation of contractual rights and operation rights allows the transfer and circulation of contracted land to other professional farmers. These linking policies would release croplands for food production and promote an appropriate scale of cropland operations with higher productivity and lower environmental impact.

To alleviate the negative externalities of institutional bottlenecks such as the Hukou system in achieving agricultural sustainability in China, the mismatch between land and labour resources in urban and rural sectors must be resolved urgently. Inefficient cropland and unused rural land (for example, rural residential land) need to be reclaimed and consolidated; productive social and economic security nets are needed for both land-lost farmers in villages and migrant rural workers in cities, aiming for long-term social sustainability after the urbanization. Context-specific pathways (for example, for China's NCP and MLYRP) that are more suitable for large-scale farming should substantively promote pro-large-scale farming and mechanization value chains. Other regions (mainly in South China) characterized by a high percentage of land fragmentation should consider integrating small farms into nearby characteristic towns (areas integrating industrial production, cultural connotation, tourism and residence with their own characteris$\operatorname{tics}^{37}$ ). This might help to provide the rural population, particularly land-lost farmers, with the majority of social services (shopping, hospitals, education and so on) and job opportunities.

Thus, the redistribution of land and labour resources between urban and rural areas can increase the efficiencies of food production, land use and economic growth and protect the environment. In fact, urbanization can not only release land in China but also benefits cropland protection in other urbanizing countries ${ }^{1}$. Urbanization and food security should be achieved at the same time to feed and settle an increasingly wealthy global population. Policies to match land and people will finally facilitate agricultural sustainability in an urbanizing world. 


\section{Methods}

To reflect the maximum potential of cropland release with urbanization, the predictions presented here are based on three assumptions: (1) new croplands are only from reclaimed rural lands; (2) there is no limit on urban development and it can occupy surrounding suitable lands including rural and natural lands (and excluding sloping land and water bodies); and (3) there is no limit on migration, rural population density remains unchanged and urban population density may either increase or decrease. We calculated a priority level for each piece of land $(1 \mathrm{~km} \times 1 \mathrm{~km})$ based on the surrounding land use attributes.

The prediction of urban expansion includes the spatial distribution of the gross domestic product (GDP). The availability of land for converting to cropland, including elevation $(\leq 3,500 \mathrm{~m})$ and slope $\left(\leq 30^{\circ}\right)$ (Supplementary Fig. 2 and http:// www.gscloud.cn/), was considered in the prediction of the amount of rural land being reclaimed. Gridded datasets of land use and GDP in 2000 and 2015 are from the Resource and Environment Data Cloud Platform (Supplementary Figs 3 and 4 , respectively $)^{31}$. The urban and rural population data at the provincial scale from National Bureau of Statistics of China (Supplementary Tables 9 and 10) were used to estimate the population densities of urban and rural built-up areas ${ }^{14}$. In addition, a SOC map was used for the analysis of soil fertility (Supplementary Fig. 5) ${ }^{38}$.

Urban expansion. We calculated the priority level of urban expansion for each grid across China. We assumed that urban expansion is continuous and will start from the boundary of current built-up areas (Supplementary Fig. 6). We set $10 \times 10$ grids to calculate the priority level at the centre of these grids (Fig. 5a). Here, priority describes the expansion of urban land outward along the boundaries of existing cities. A higher proportion of urban land within the $10 \times 10$ grids indicates a more likely chosen grid for expansion. We set the value of urban land to 1 and all the other uses of land to 0 on the 2015 land use map (Fig. 5b) and analysed the potential distribution of new urban lands using the Focal Statistics tool in ArcGIS version 10.6. We counted the number of these two land types within the 100 grids and calculated the priority level for the central grid using equation (1):

$$
\rho=\frac{c}{100}
$$

where $c$ is the number of urban grids within these 100 grids, and $\rho$ refers to urban expansion priority. We calculated $\rho$ (Fig. $5 \mathrm{c}$ ) and ranked the results following the priority level for all grids across China (Fig. 5d, Supplementary Table 11 and Supplementary Fig. 6b). If there were two grids with the same $\rho$, we ranked them using GDP, with a higher GDP preferred for urban development (Supplementary Fig. 4).

Rural land reclamation. In the simulation of rural built-up area reclamation, we mainly considered whether there was a large amount of cropland around the homestead; otherwise, it would not be reclaimed or it would instead be returned to natural, unmanaged land, which is common in the southern mountainous areas. For instance, restoration of forest vegetation to abandoned rural homesteads in some islands in East China has occurred. Similar to urban expansion, we estimated the degree of rural land reclaimed by calculating the priority level for all of the grids across China. As continuous croplands are best suited for large-scale farming, we gave high priority to rural lands surrounded by croplands. We set $3 \times 3$ grids to calculate the priority level of reclaiming rural land at the centre of these grids (Fig. 5e). We set the values of cropland and rural land to 1 and 10, respectively, on the 2015 land use map (Fig. 5f) and analysed the potential distribution of new croplands using the Focal Statistics tool in ArcGIS version 10.6. We counted the number of the two land use types in the nine grids and calculated the priority level for the central grid using equation (2):

$$
\theta=\frac{a+b}{a}
$$

where $a$ and $b$ are the number of rural and cropland grids, respectively, within the nine grids, and $\theta$ refers to the priority level of reclaiming rural land. We calculated $\theta$ (Fig. $5 \mathrm{~g}$ ) and ranked the results following the priority level for all grids across China (Fig. 5h, Supplementary Table 12 and Supplementary Fig. 7). If there were two grids with the same $\theta$ value, we ranked them using a second-round calculation based on $9 \times 9$ grids following equation (2), with a higher value of $\theta$ being preferred for rural land being reclaimed (Supplementary Table 13 and Supplementary Fig. 8).

Change of crop production. We estimated the changes in crop production through the changes of cropland area and SOC (3):

$$
\mathrm{CP}=\frac{\text { area }_{2}}{\text { area }_{1}} \times \frac{\mathrm{SOC}_{2}}{\mathrm{SOC}_{1}}
$$

where $\mathrm{CP}$ is the crop production in a county, area $\mathrm{a}_{1}$ and area $_{2}$ are the cropland area in a county for two different years, and $\mathrm{SOC}_{1}$ and $\mathrm{SOC}_{2}$ are the content of the SOC in a county for two different years. We did not consider such changes in cropland management as fertilization.

Change in farm size. We used the changes of per-capita cropland area of rural residents to indicate the changes in farm size. Estimation of the changes in farm size was based on the changes in total cropland area and rural residents within a county (equation (4)):

$$
\begin{aligned}
& \gamma=\frac{\partial_{2}-\partial_{1}}{\partial_{1}} \\
& \partial=\frac{S}{P}
\end{aligned}
$$

where $\gamma$ is a county's change in farm size, $\partial_{1}$ and $\partial_{2}$ are a county's rural residents' per-capita cropland area for two different years, $S$ is a county's cropland area and $P$ is a county's rural population.

Sensitivity analysis. The future urban population density was crucial for the analysis. With an increasing population and less land area per capita, the pressure on food production is still substantial in China. Currently, China imports around 1 million tonnes of grain per annum, and the trend is growing ${ }^{14}$. Therefore, food security has always been the top priority of central government, with the No. 1 Central Document focusing on agricultural and rural issues for many years ${ }^{39}$. In addition, the central government has established a red line for cropland protection. In recent years, there have been restrictions on the construction of villas and golf courses in major cities. These factors indicate that the future urban population density is unlikely to decrease. Historical data show that the population density slightly increased in urban areas, while it decreased in rural areas (Supplementary Table 15). More land would be released if the urban population density continues to increase in the future. However, no matter how the urban population density changes as a consequence of migration and ageing, it is generally higher than in rural areas, which will lead to the release of cropland for urbanization. Therefore, a change of urban population density, while affecting the results of this study, will not change our conclusions (Supplementary Figs 15-18 and Supplementary Tables 3-7)

To reflect these potential changes, we considered two urban population density scenarios. The low urban population density scenario suggests a $48 \%$ decrease, while the high urban population density scenario suggests a $45 \%$ increase in 2050 (compared with the 2015 baseline) following future projections ${ }^{40}$. Rural population density may also change, but it is difficult to project how, and its impact on land use is diminishing with increased urbanization. Thus, the effects of rural density changes were excluded from the analysis conducted in this study.

Reporting Summary. Further information on research design is available in the Nature Research Reporting Summary linked to this article.

\section{Data availability}

The data supporting the findings of this study beyond those provided in the Supplementary Information are all from open-source databases or literature citations. Source data are provided with this paper.

Received: 27 April 2020; Accepted: 15 January 2021; Published online: 11 March 2021

\section{References}

1. Gu, B., Zhang, X., Bai, X., Fu, B. \& Chen, D. Four steps to food security for swelling cities. Nature 566, 31-33 (2019).

2. Godfray, H. C. et al. Food security: the challenge of feeding 9 billion people. Science 327, 812-818 (2010).

3. Bren D Amour, C. et al. Future urban land expansion and implications for global croplands. Proc. Natl Acad. Sci. USA 114, 8939-8944 (2017).

4. Gardi, C., Panagos, P., Van Liedekerke, M., Bosco, C. \& De Brogniez, D. Land take and food security: assessment of land take on the agricultural production in Europe. J. Environ Plann. Manag. 58, 898-912 (2015).

5. Shi, K. et al. Urban expansion and agricultural land loss in China: a multiscale perspective. Sustainability 8, 790 (2016).

6. Bai, X., Shi, P. \& Liu, Y. Society: realizing China's urban dream. Nature 509, 158-160 (2014)

7. World Urbanization Prospects 2018 (United Nations, 2018); https://population un.org/wup/Download/

8. Zhai, Z., Chen, J. \& Li, L. Future trends of China's population and aging from 2015 to 2100 [in Chinese]. Popul. Res. 41, 60-71 (2017).

9. Van Vliet, J., Eitelberg, D. A. \& Verburg, P. H. A global analysis of land take in cropland areas and production displacement from urbanization. Glob. Environ. Change 43, 107-115 (2017).

10. Chen, J. Rapid urbanization in China: a real challenge to soil protection and food security. Catena 69, 1-15 (2007).

11. Martellozzo, F. et al. Urbanization and the loss of prime farmland: a case study in the Calgary-Edmonton corridor of Alberta. Reg. Environ. Change 15, 881-893 (2015).

12. Yan, H., Liu, J., He, Q. H., Bo, T. \& Cao, M. Assessing the consequence of land use change on agricultural productivity in China. Glob. Planet. Change 67, 13-19 (2009).

13. Bai, X., Chen, J. \& Shi, P. Landscape urbanization and economic growth in China: positive feedbacks and sustainability dilemmas. Environ. Sci. Technol. 46, 132-139 (2012). 
14. Statistical yearbooks of prefecture-level cities in 2015 [in Chinese]. National Bureau of Statistics http://www.stats.gov.cn/tjsj/ (2016).

15. Zuo, L. et al. Progress towards sustainable intensification in China challenged by land-use change. Nat. Sustain. 1, 304-313 (2018).

16. Lal, R. Soil carbon sequestration impacts on global climate change and food security. Science 304, 1623-1627 (2004).

17. Zhang, X. et al. Effects of enhancing soil organic carbon sequestration in the topsoil by fertilization on crop productivity and stability: evidence from long-term experiments with wheat-maize cropping systems in China. Sci. Total Environ. 562, 247-259 (2016)

18. $\mathrm{Wu}, \mathrm{Y}$. et al. Policy distortions, farm size, and the overuse of agricultural chemicals in China. Proc. Natl Acad. Sci. USA 115, 7010-7015 (2018).

19. Zou, B., Mishra, A. K. \& Luo, B. Aging population, farm succession, and farmland usage: evidence from rural China. Land Use Policy 77, 437-445 (2018)

20. Guidance on Accelerating the Development of Agricultural Productive Services (Ministry of Agriculture and Rural Affairs of the People's Republic of China, 2017).

21. Ju, X., Gu, B., Wu, Y. \& Galloway, J. N. Reducing China’s fertilizer use by increasing farm size. Glob. Environ. Change 41, 26-32 (2016).

22. Ren, C. et al. The impact of farm size on agricultural sustainability. J. Clean Prod. 220, 357-367 (2019).

23. Adamopoulos, T. \& Restuccia, D. The size distribution of farms and international productivity differences. Am. Econ. Rev. 104, 1667-1697 (2014).

24. Wang, J., Chen, K. Z., Gupta, S. D. \& Huang, Z. Is small still beautiful? A comparative study of rice farm size and productivity in China and India. China Agr. Econ. Rev. 7, 484-509 (2015).

25. Lu, H., Xie, H., He, Y., Wu, Z. \& Zhang, X. Assessing the impacts of land fragmentation and plot size on yields and costs: a translog production model and cost function approach. Agr. Syst. 161, 81-88 (2018).

26. Syp, A., Faber, A., Borzecka-Walker, M. \& Osuch, D. Assessment of greenhouse gas emissions in winter wheat farms using data envelopment analysis approach. Pol. J. Environ. Stud. 24, 2197-2203 (2015).

27. Li, G., Feng, Z., You, L. \& Fan, L. Re-examining the inverse relationship between farm size and efficiency. China Agr. Econ. Rev. 5, 473-488 (2013).

28. Fan, L. et al. Decreasing farm number benefits the mitigation of agricultural non-point source pollution in China. Environ. Sci. Pollut. Res. 26, 464-472 (2019).

29. Cassman, K. G., Dobermann, A., Walters, D. T. \& Yang, H. Meeting cereal demand while protecting natural resources and improving environmental quality. Annu. Rev. Env. Resour. 28, 315-358 (2003).

30. Pellegrini, P. \& Fernández, R. J. Crop intensification, land use, and on-farm energy-use efficiency during the worldwide spread of the green revolution. Proc. Natl Acad. Sci. USA 115, 2335-2340 (2018).

31. Resource and Environment Data Cloud Platform (Resource and Environment Science and Data Center, 2018); http://www.resdc.cn/Default.aspx

32. Laborde, D., Martin, W., Swinnen, J. \& Vos, R. COVID-19 risks to global food security. Science 369, 500-502 (2020).

33. Shi, Q., Jin, H. \& Zhuo, J. Does land expropriation definitely reduce farmers income: a survey of 7 villages in Shanghai: the defects and reforms of the current land expropriation system [in Chinese]. Manage. World 3, 77-82 (2011).
34. Liu, Y. \& Li, Y. Revitalize the world's countryside. Nature 548, 275-277 (2017)

35. Liu, Y., Fang, F. \& Li, Y. Key issues of land use in China and implications for policy making. Land Use Policy 40, 6-12 (2014).

36. Measures for Land Acquisition Compensation and Social Security for Land-Expropriated Farmers in Jiangsu Province Provincial Government Order No. 93 (Jiangsu Provincial People's Government, 2013).

37. Wu, Y., Chen, Y., Deng, X. \& Hui, E. C. M. Development of characteristic towns in China. Habitat Int. 77, 21-31 (2018).

38. Yu, Y., Huang, Y. \& Zhang, W. Modeling soil organic carbon change in croplands of China, 1980-2009. Glob. Planet Change 82-83, 115-128 (2012).

39. No. 1 Central Document (Ministry of Agriculture and Rural Affairs of the People's Republic of China, 2020); http://www.moa.gov.cn/ztzl/jj2020zyyhwj/

40. Güneralp, B. et al. Global scenarios of urban density and its impacts on building energy use through 2050. Proc. Natl Acad. Sci. USA 114, 8945-8950 (2017)

\section{Acknowledgements}

This study was supported by the National Natural Science Foundation of China (41822701, 41773068, 41721001 and 71834005), National Key Research and Development Project of China (2018YFC0213300), Discovery Early Career Researcher Award of the Australian Research Council (DE170100423) and Fundamental Research Funds for the Central Universities (2019XZZX004-11). The work of S.R. was supported by the UK Natural Environment Research Council (NERC) national capability award NE/R000131/1 (Sustainable Use of Natural Resources to Improve Human Health and Support Economic Development (SUNRISE)) and award number NE/R016429/1 as part of the UK-SCAPE programme delivering national capability.

\section{Author contributions}

B.G. designed the study. S.W. conducted the research. B.G. and S.W. wrote the first draft of the paper. X.Z., X.B., D.C., J.X. and S.R. revised the paper. All authors contributed to discussion and revision of the paper.

\section{Competing interests}

The authors declare no competing interests.

\section{Additional information} Extended data is available for this paper at https://doi.org/10.1038/s43016-021-00228-6. Supplementary information The online version contains supplementary material available at https://doi.org/10.1038/s43016-021-00228-6.

Correspondence and requests for materials should be addressed to B.G.

Peer review information Nature Food thanks Xuejun Liu, Xin Zhao and the other, anonymous, reviewer(s) for their contribution to the peer review of this work.

Reprints and permissions information is available at www.nature.com/reprints. Publisher's note Springer Nature remains neutral with regard to jurisdictional claims in published maps and institutional affiliations.

(c) The Author(s), under exclusive licence to Springer Nature Limited 2021 


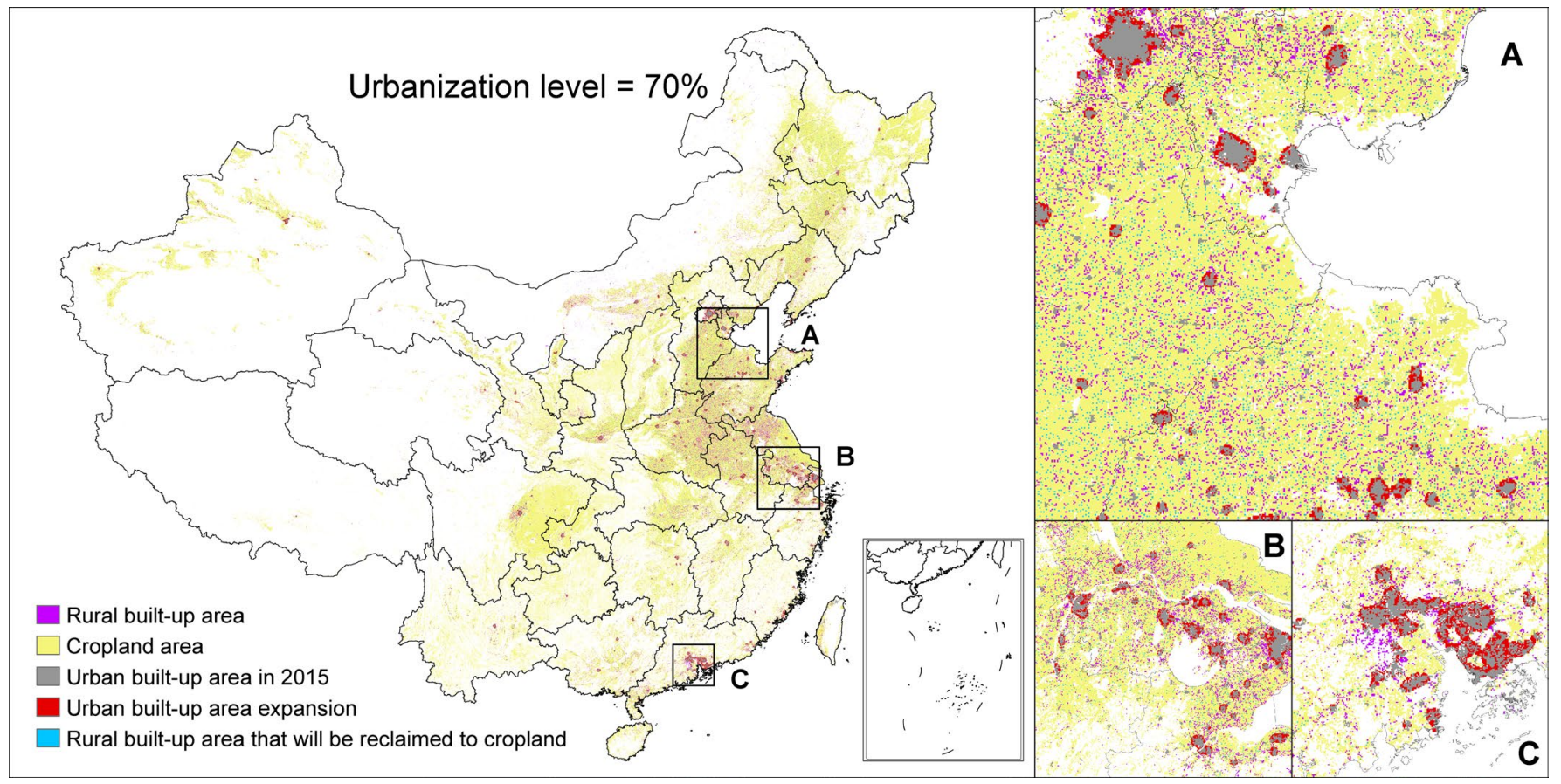

Extended Data Fig. 1 | Spatial changes of land use with an urbanization level of 70\% in 2030. From 2015 to 2030, new released croplands are concentrated in the NCP, Middle and Lower Yangtze River Basin, and Northeast Plain, while the intensive areas of urban expansion are the Beijing-Tianjin-Hebei region, the Yangtze River Delta, and the Pearl River Delta. Base map is applied without endorsement from GADM data (https://gadm.org/). 


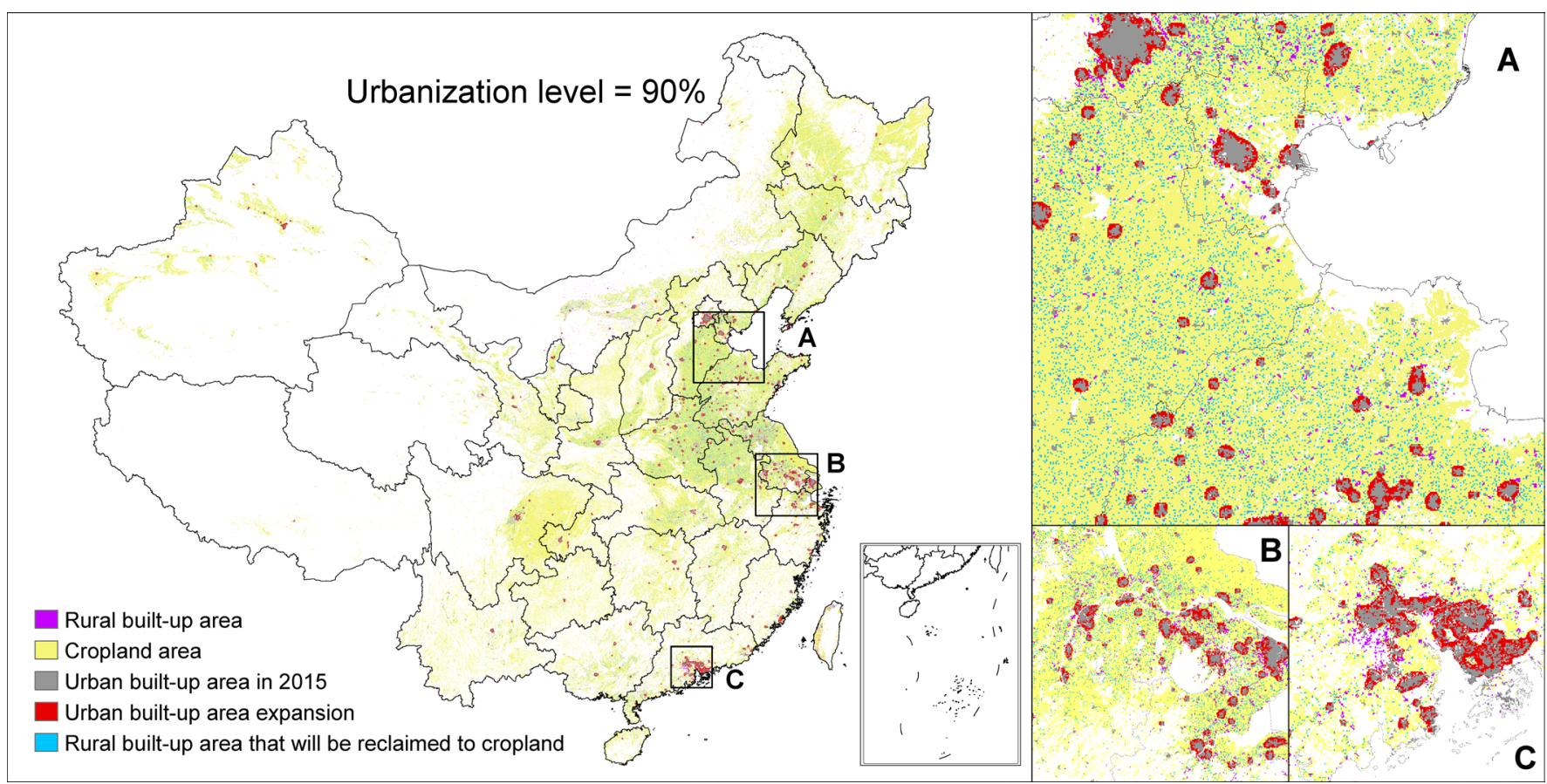

Extended Data Fig. 2 | Spatial changes in land use with an urbanization level of $\mathbf{9 0 \%}$ in 2050. From 2015 to 2050, new released croplands are concentrated in the NCP, Middle and Lower Yangtze River Basin, and Northeast Plain, while the hot spots for urban expansion are the Beijing-Tianjin-Hebei region, Yangtze River Delta, and Pearl River Delta. Extended Data Fig. 1 and 2 show the distribution maps of land use changes from urbanization level 56\%, 70\%, and $80 \%$ for 2015, 2030 and 2050, respectively. Base map is applied without endorsement from GADM data (https://gadm.org/). 

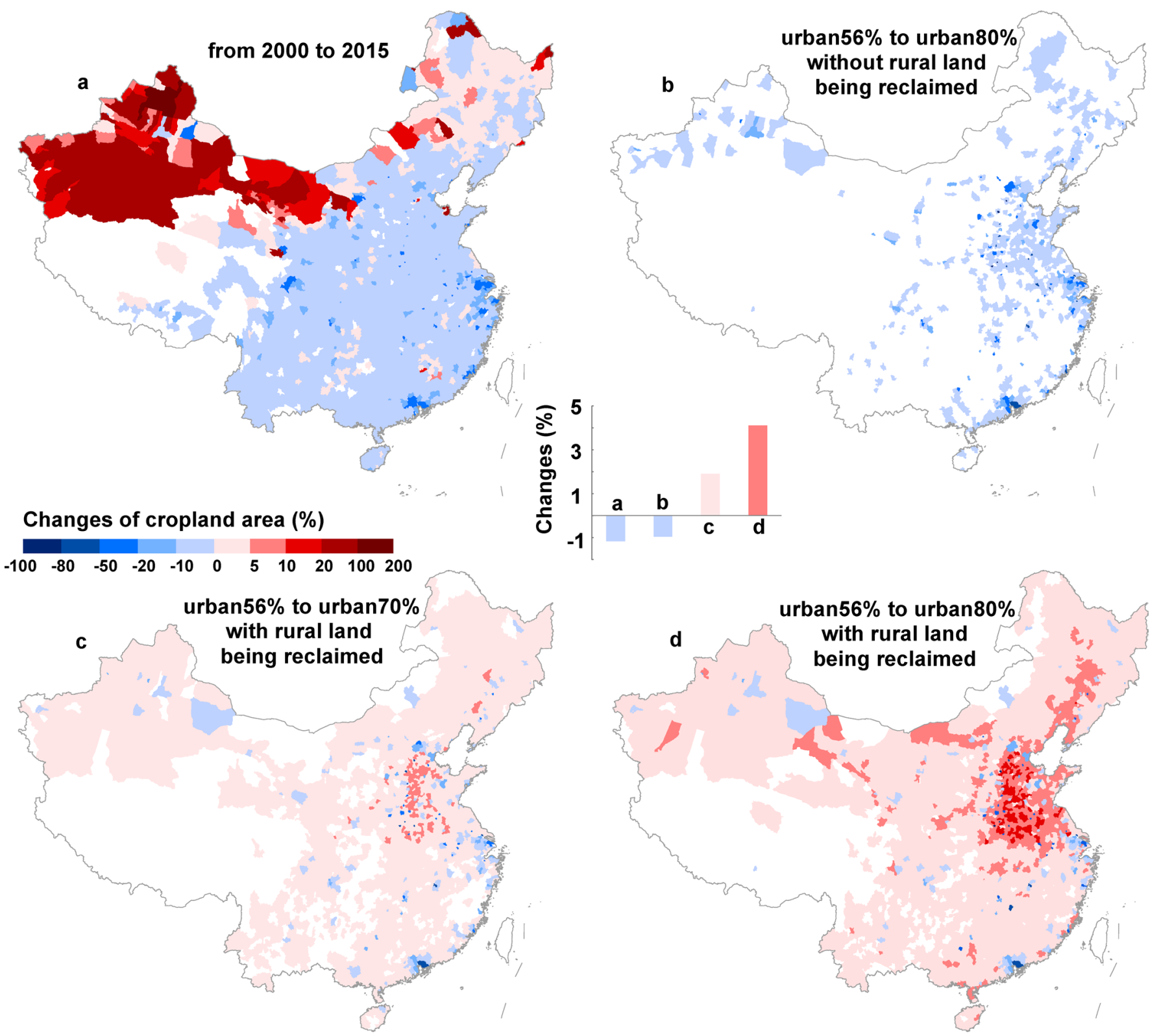

Extended Data Fig. 3 | Changes in cropland area at the county level. (a) From 2000 to 2015; (b) From urbanization level 56\% (2015) to urbanization level $80 \%$ (2050) without rural land being reclaimed; (c) From urbanization level 56\% (2015) to urbanization level 70\% (2030) with rural land being reclaimed; (d) From urbanization level 56\% (2015) to urbanization level 80\% (2050) with rural land being reclaimed. The bar chart in the middle of the Figure shows the overall changes for 2000-2015 and each scenario in the future for China as a whole (Supplementary Table 3). Base map is applied without endorsement from GADM data (https://gadm.org/). 

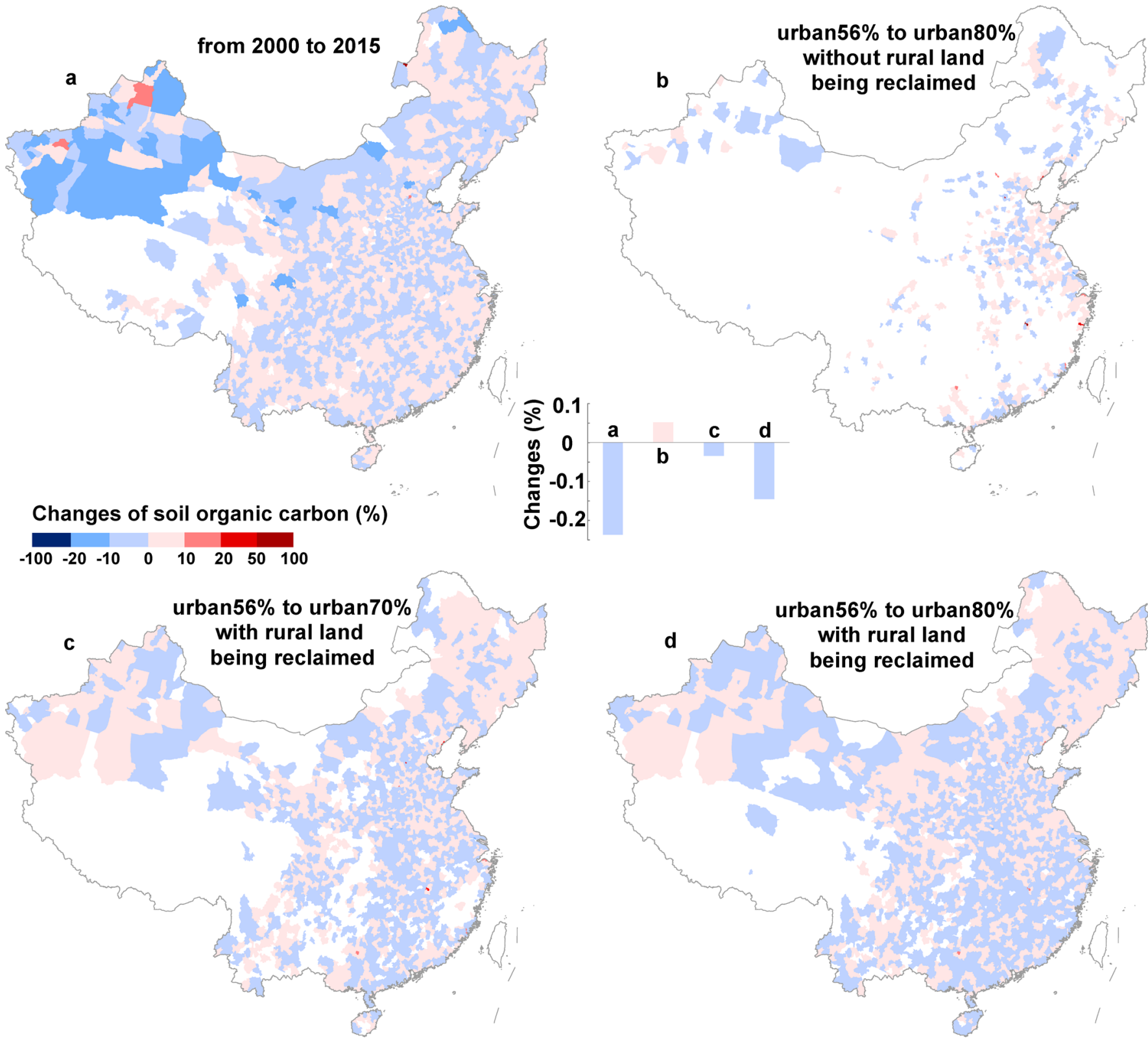

Extended Data Fig. 4 | Changes of soil organic carbon at the county level. (a) From 2000 to 2015; (b) From urbanization level 56\% (2015) to urbanization level 80\% (2050) without rural land being reclaimed; (c) From urbanization level 56\% (2015) to urbanization level 70\% (2030) with rural land being reclaimed; (d) From urbanization level 56\% (2015) to urbanization level 80\% (2050) with rural land being reclaimed. The bar chart in the middle of the Extended Data Fig. 4 shows the overall changes for 2000-2015 and each scenario in the future, taking China as a whole (Supplementary Table 4). Base map is applied without endorsement from GADM data (https://gadm.org/). 


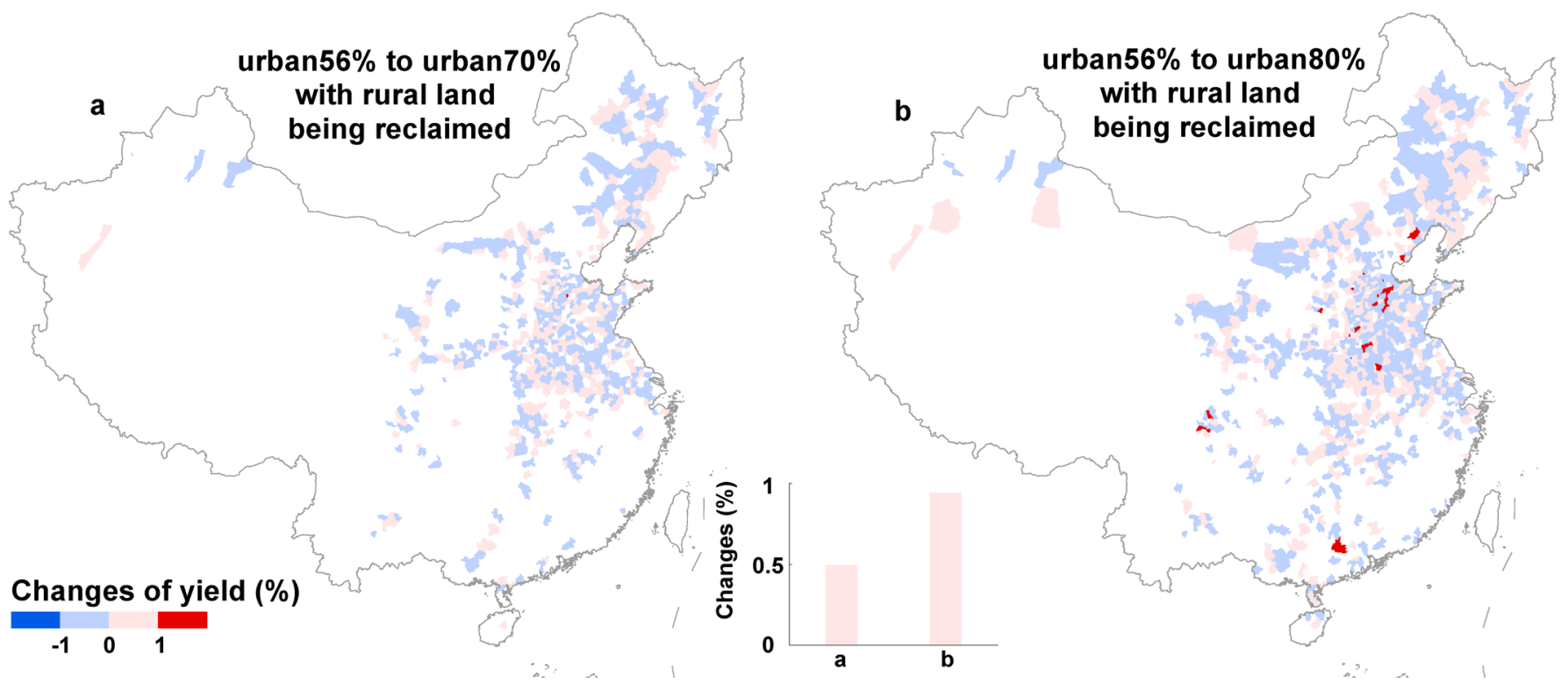

Extended Data Fig. 5 | Changes in yield. (a) From urbanization level 56\% (2015) to urbanization level 70\% (2030) with rural land being reclaimed; (b) From urbanization level 56\% (2015) to urbanization level $80 \%$ (2050) with rural land being reclaimed. The bar chart in the middle of the figure shows the overall changes for each scenario in the future for China as a whole (Supplementary Table 5). Supplementary Fig. 14 shows the yield in major cereal in 2015. Base map is applied without endorsement from GADM data (https://gadm.org/). 

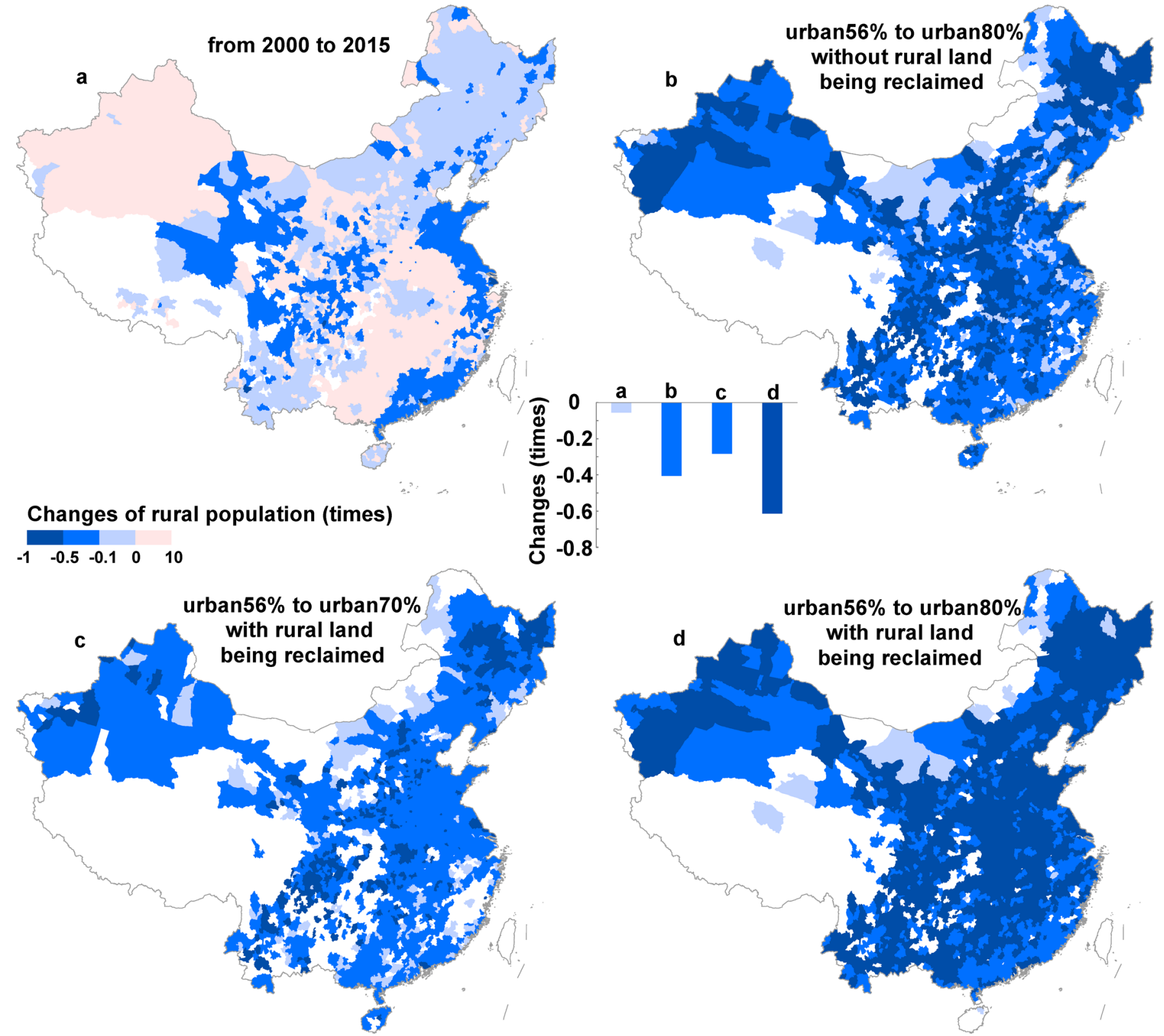

Extended Data Fig. 6 | Changes in rural population. (a) From 2000 to 2015; (b) From urbanization level 56\% (2015) to urbanization level 80\% (2050) without rural land being reclaimed; (c) From urbanization level 56\% (2015) to urbanization level 70\% (2030) with rural land being reclaimed; (d) From urbanization level 56\% (2015) to urbanization level 80\% (2050) with rural land being reclaimed. (a) and (b) estimate the registered population, while (c) and (d) estimate the resident population. The bar chart in the middle of the Figure shows the overall changes for 2000-2015 and each scenario in the future, taking China as a whole (Supplementary Table 8). Base map is applied without endorsement from GADM data (https://gadm.org/). 

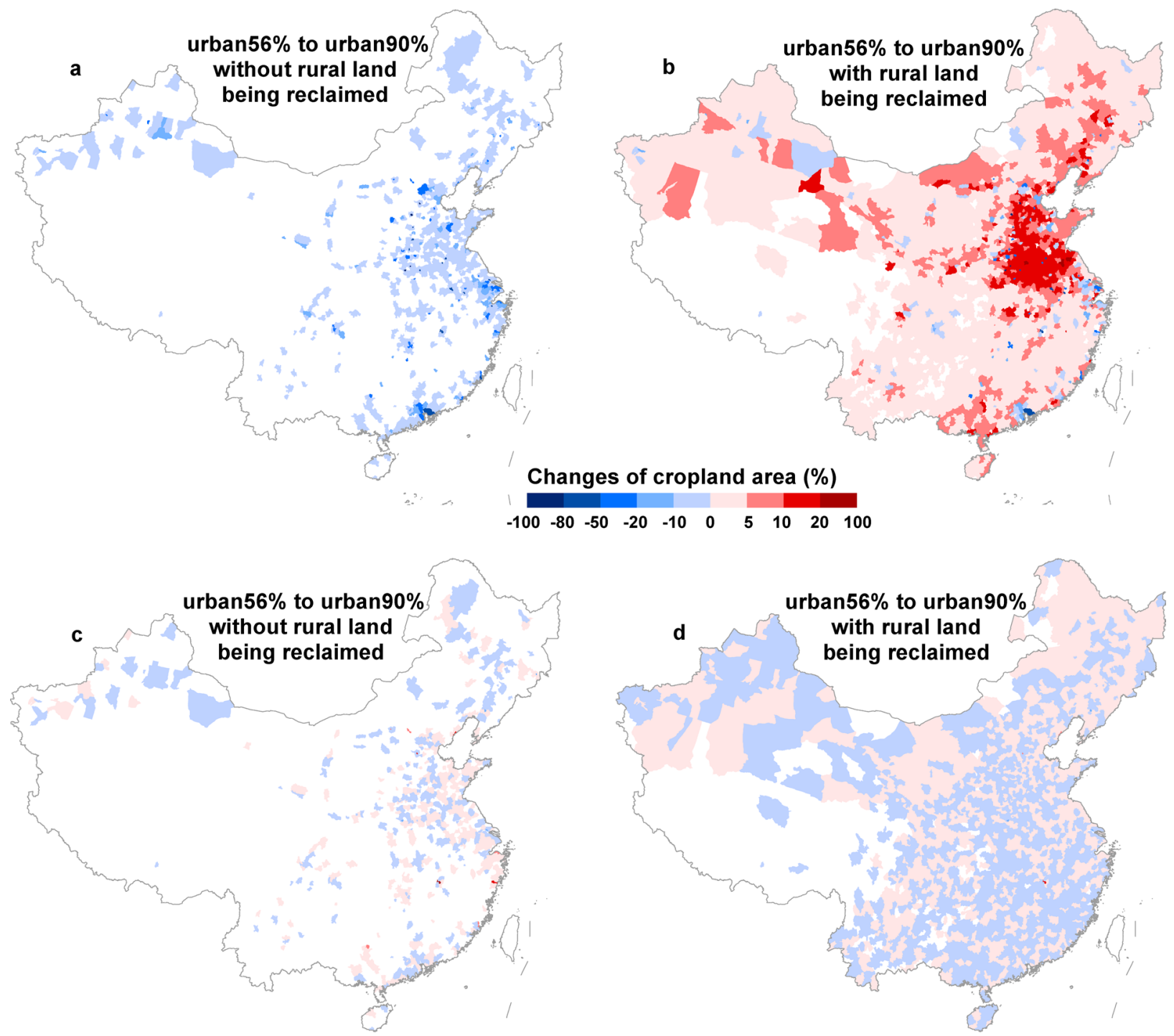

Changes of soil organic carbon (\%)

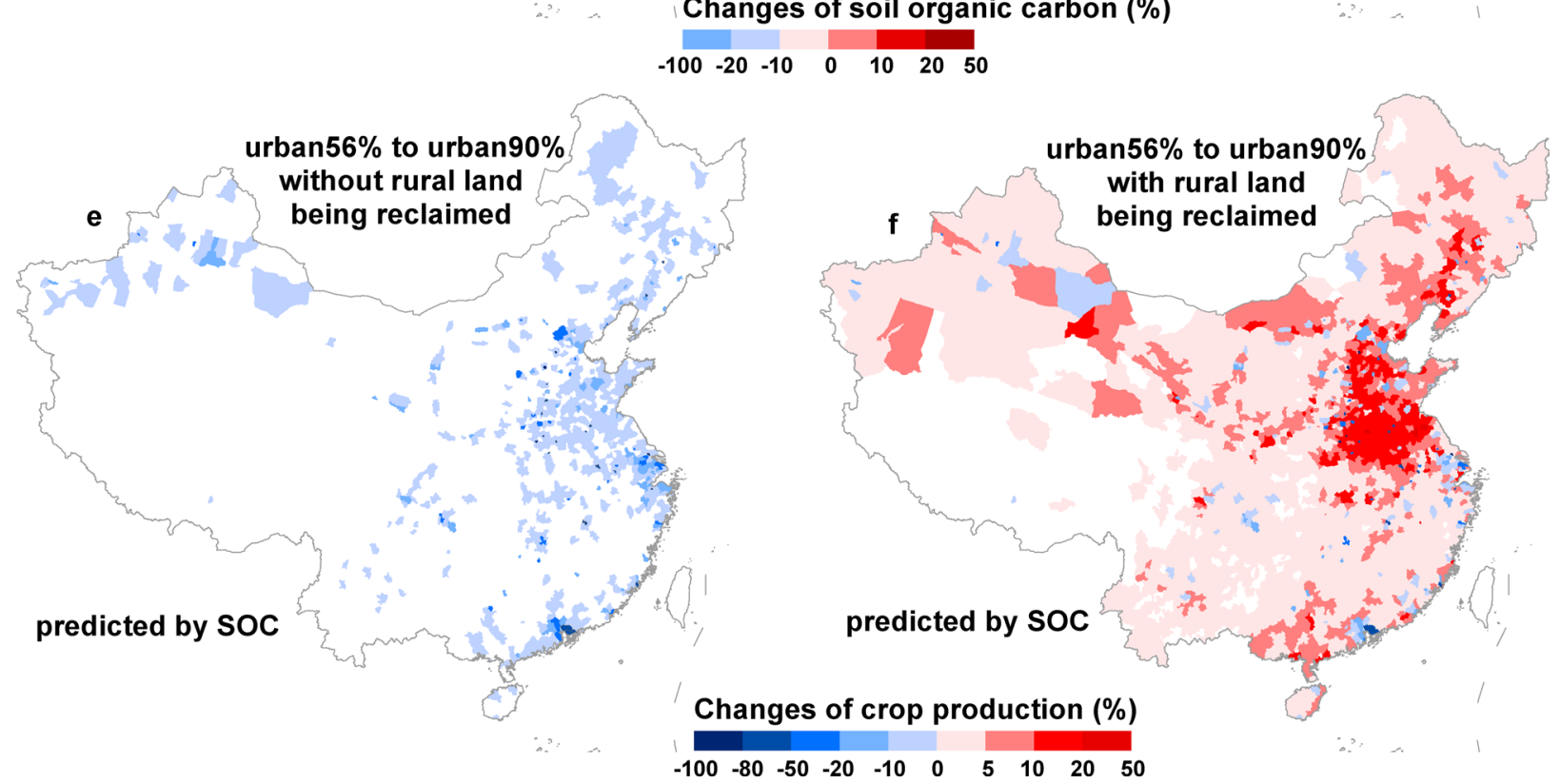

Extended Data Fig. 7 | See next page for caption. 
Extended Data Fig. 7 | Changes in cropland area, soil organic carbon, and crop production at the county level. (a) Changes in cropland area from urbanization level 56\% (2015) to urbanization level 90\% (2050) without rural land being reclaimed; (b) Changes of cropland area from urbanization level 56\% (2015) to urbanization level 90\% (2050) with rural land being reclaimed; (c) Changes of soil organic carbon from urbanization level 56\% (2015) to urbanization level 90\% (2050) without rural land being reclaimed; (d) Changes of soil organic carbon from urbanization level 56\% (2015) to urbanization level 90\% (2050) with rural land being reclaimed; (e) Changes of crop production from urbanization level 56\% (2015) to urbanization level 90\% (2050) without rural land being reclaimed, predicted by SOC; (f) Changes of crop production from urbanization level 56\% (2015) to urbanization level $90 \%$ (2050) with rural land being reclaimed, predicted by SOC. Base map is applied without endorsement from GADM data (https://gadm.org/). 

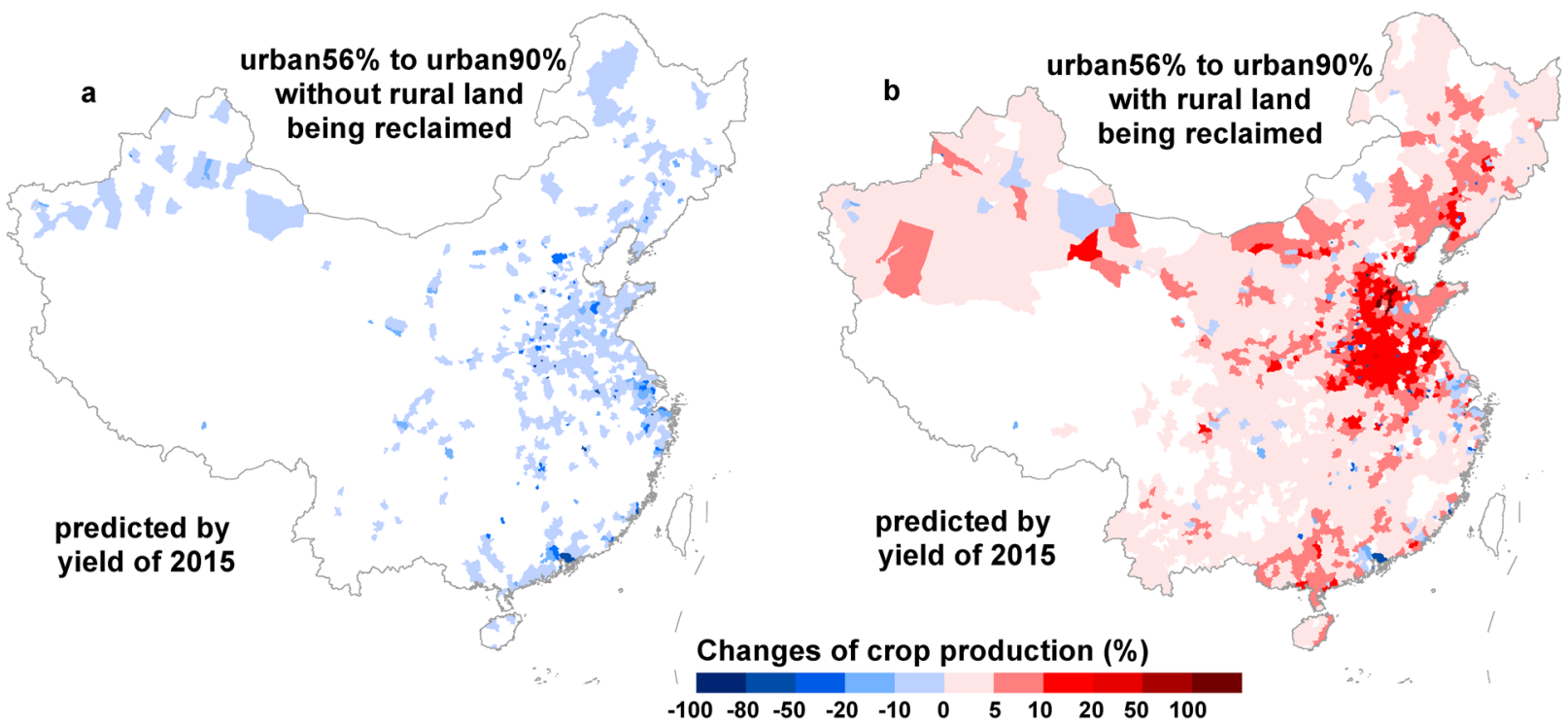

Changes of crop production (\%)

$\begin{array}{lllllllllll}-100 & -80 & -50 & -20 & -10 & 0 & 5 & 10 & 20 & 50 & 100\end{array}$

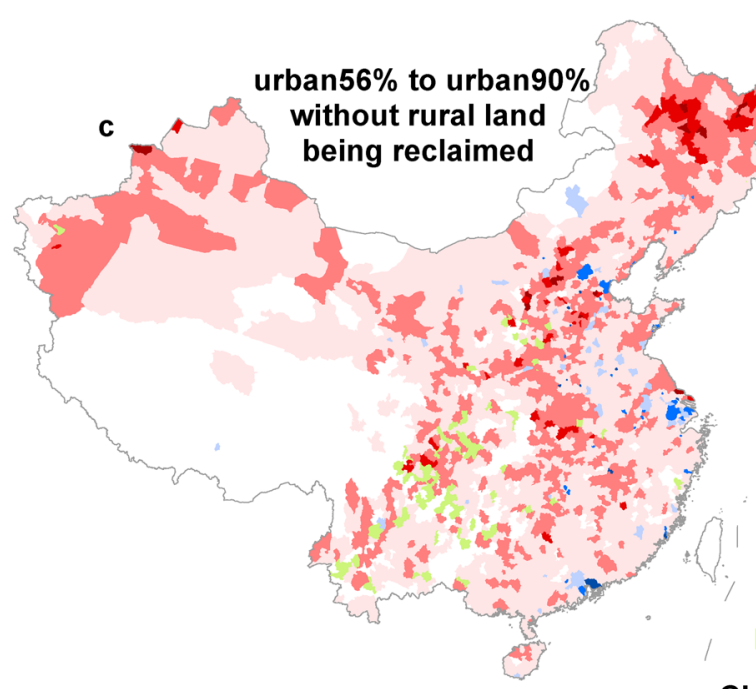

No rural residents

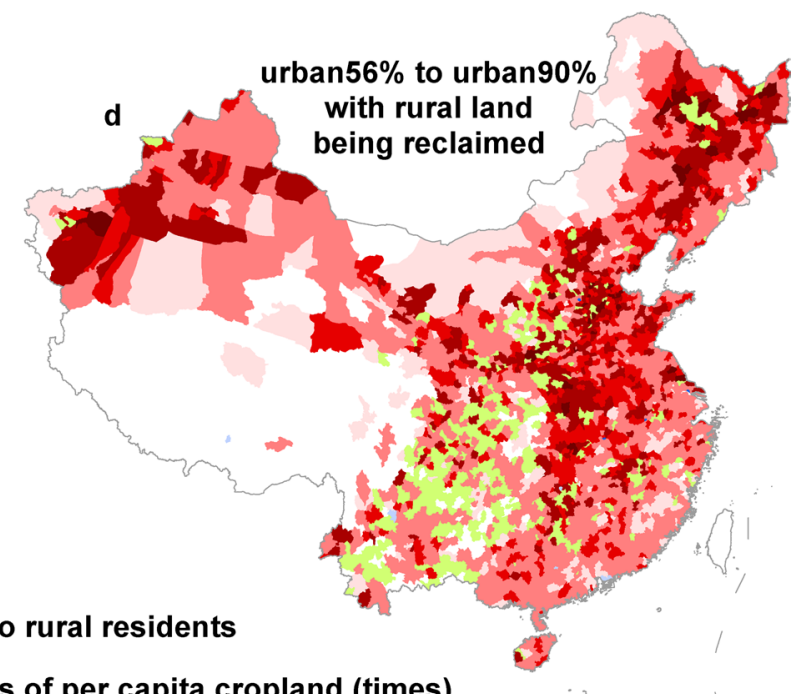

Changes of per capita cropland (times)
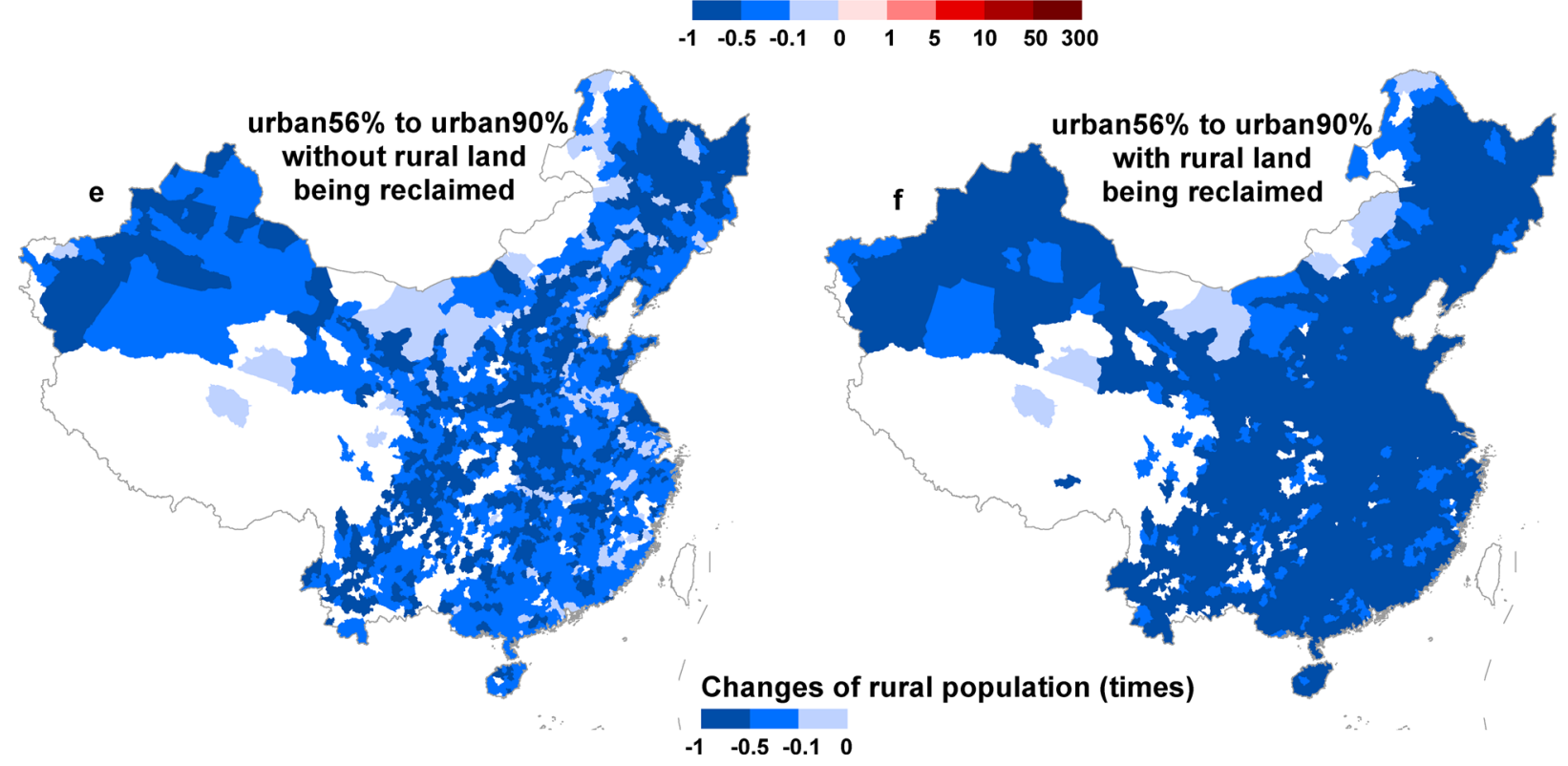

Extended Data Fig. 8 | See next page for caption. 
Extended Data Fig. 8 | Changes in crop production, per capita cropland, and rural population at the county level. (a) Changes in crop production from urbanization level 56\% (2015) to urbanization level 90\% (2050) without rural land being reclaimed, predicted by the yield of 2015; (b) Changes of crop production from urbanization level 56\% (2015) to urbanization level $90 \%$ (2050) with rural land being reclaimed, predicted by the yield of 2015; (c) Changes of per capita cropland from urbanization level 56\% (2015) to urbanization level 90\% (2050) without rural land being reclaimed; (d) Changes of per capita cropland from urbanization level 56\% (2015) to urbanization level 90\% (2050) with rural land being reclaimed; (e) Changes of rural population from urbanization level 56\% (2015) to urbanization level $90 \%$ (2050) without rural land being reclaimed; (f) Changes of rural population from urbanization level 56\% (2015) to urbanization level 90\% (2050) with rural land being reclaimed. Base map is applied without endorsement from GADM data (https://gadm.org/). 


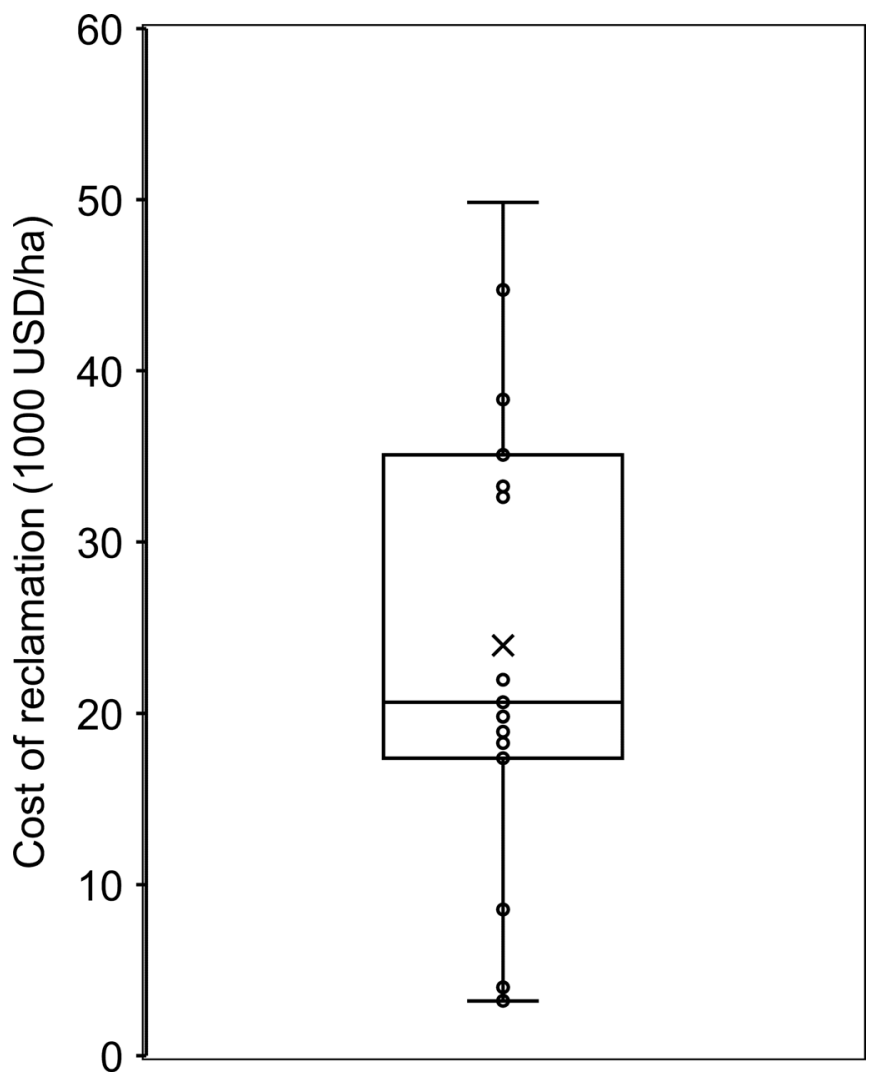

Extended Data Fig. 9 | Cost of reclamation (1000 USD/ha). All data are from the records of the website of China Land Consolidation and Rehabilitation after 2017 (http://www.Icrc.org.cn/tdzzgz/zxgz/gbzntjs/). 


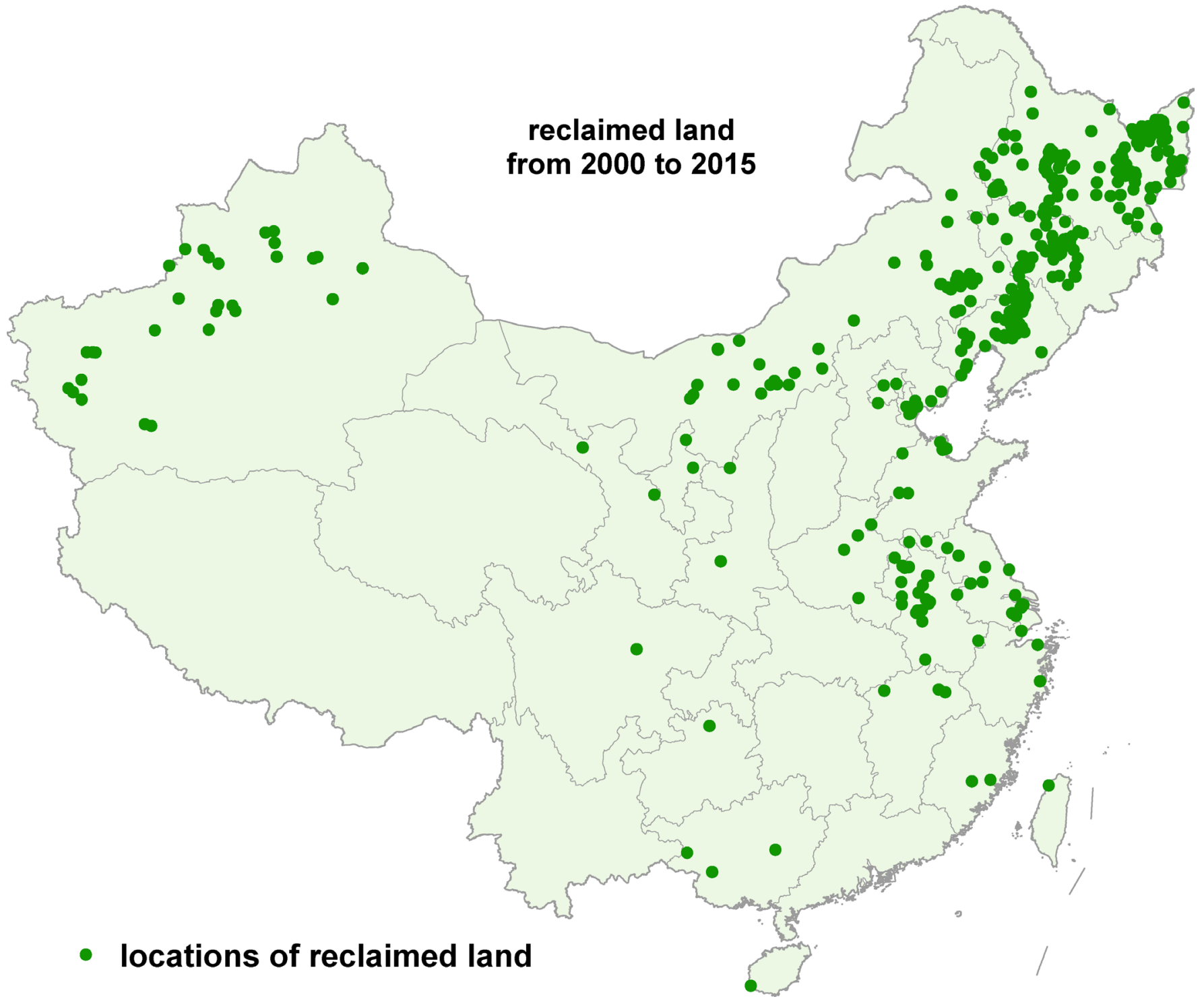

Extended Data Fig. 10 | Locations of reclaimed land from 2000 to 2015. Gridded datasets of land use and GDP in 2000 and 2015 are from the Resource and Environment Data Cloud Platform (http://www.resdc.cn/Default.aspx). Base map is applied without endorsement from GADM data (https://gadm.org/). 


\section{Reporting Summary}

Nature Research wishes to improve the reproducibility of the work that we publish. This form provides structure for consistency and transparency in reporting. For further information on Nature Research policies, see our Editorial Policies and the Editorial Policy Checklist.

\section{Statistics}

For all statistical analyses, confirm that the following items are present in the figure legend, table legend, main text, or Methods section.

n/a Confirmed

Х $\square$ The exact sample size $(n)$ for each experimental group/condition, given as a discrete number and unit of measurement

Х $\square$ A statement on whether measurements were taken from distinct samples or whether the same sample was measured repeatedly

$\square$ The statistical test(s) used AND whether they are one- or two-sided

Х $\square$ Only common tests should be described solely by name; describe more complex techniques in the Methods section.

Х $\square$ A description of all covariates tested

$\square$ \A description of any assumptions or corrections, such as tests of normality and adjustment for multiple comparisons

$\varnothing \square$ A full description of the statistical parameters including central tendency (e.g. means) or other basic estimates (e.g. regression coefficient)

$\triangle \square$ AND variation (e.g. standard deviation) or associated estimates of uncertainty (e.g. confidence intervals)

$\bigotimes \square \begin{aligned} & \text { For null hypothesis testing, the test statistic (e.g. } F, t, r \text { ) with confidence intervals, effect sizes, degrees of freedom and } P \text { value noted } \\ & \text { Give } P \text { values as exact values whenever suitable. }\end{aligned}$

Х $\square$ For Bayesian analysis, information on the choice of priors and Markov chain Monte Carlo settings

Х $\square$ For hierarchical and complex designs, identification of the appropriate level for tests and full reporting of outcomes

Х $\square$ Estimates of effect sizes (e.g. Cohen's $d$, Pearson's $r$ ), indicating how they were calculated

Our web collection on statistics for biologists contains articles on many of the points above.

\section{Software and code}

Policy information about availability of computer code

Data collection No software was used for data collection.

Data analysis The spatial statistics was conducted by using ArcGIS 10.6, which is available at https://desktop.arcgis.com/

For manuscripts utilizing custom algorithms or software that are central to the research but not yet described in published literature, software must be made available to editors and reviewers. We strongly encourage code deposition in a community repository (e.g. GitHub). See the Nature Research guidelines for submitting code \& software for further information.

\section{Data}

Policy information about availability of data

All manuscripts must include a data availability statement. This statement should provide the following information, where applicable:

- Accession codes, unique identifiers, or web links for publicly available datasets

- A list of figures that have associated raw data

- A description of any restrictions on data availability

Our analysis mainly uses land-use and GDP spatial distribution data from Resource and Environment Data Cloud Platform of Institute of Geographic Sciences and Natural Resources Research, CAS (http://www.resdc.cn/Default.aspx), elevation and slope data from http://www.gscloud.cn/, SOC map is from Yu, Y. et al (2012), crop production data and population statistical data from National Bureau of Statistics (http://www.stats.gov.cn/tjsj/). 


\section{Field-specific reporting}

Please select the one below that is the best fit for your research. If you are not sure, read the appropriate sections before making your selection.
Life sciences
$\square$ Behavioural \& social sciences
$\bigotimes$ Ecological, evolutionary \& environmental sciences

For a reference copy of the document with all sections, see nature.com/documents/nr-reporting-summary-flat.pdf

\section{Ecological, evolutionary \& environmental sciences study design}

All studies must disclose on these points even when the disclosure is negative.

Study description

Research sample

Sampling strategy

Data collection

Timing and spatial scale

Data exclusions

Reproducibility

Randomization

Blinding
By using spatial statistics and scenario analysis, we analyze and quantify the potential amount of cropland release from China's urbanization between 2015 and 2030 (anticipated peak population level) and 2050 (projected peak urbanization level), informed by 2000-2015 empirical data for cropland and built-up area changes in both urban and rural areas.

The research sample is 2000-2015 empirical data for cropland, built-up area and population changes in both urban and rural areas. Sampling strategy is no relevant to our study.

The spatial data our analysis mainly use are directly from database Resource and Environment Data Cloud Platform and population statistic data are directly from National Bureau of Statistics.

Timing scale: cross-sectional data of 2000 and 2015 for historical analysis. Spatial scale: it covers 2311 counties of all 31 provinces in China mainland.

No data were excluded.

Our data are available on model is simply designed, everyone can reproduce the result.

Randomization is no relevant to our study.

Blinding is not relevant to this study, as no treatment is applied.

Did the study involve field work? $\square$ Yes $\quad$ No

\section{Reporting for specific materials, systems and methods}

We require information from authors about some types of materials, experimental systems and methods used in many studies. Here, indicate whether each material, system or method listed is relevant to your study. If you are not sure if a list item applies to your research, read the appropriate section before selecting a response.

\begin{tabular}{|c|c|}
\hline $\mathrm{n} / \mathrm{a}$ & Involved in the study \\
\hline Х & Antibodies \\
\hline$\bigotimes$ & Eukaryotic cell lines \\
\hline$\bigotimes$ & Palaeontology and archaeology \\
\hline$\bigotimes$ & Animals and other organisms \\
\hline$\bigotimes$ & Human research participants \\
\hline$\bigotimes$ & $\square$ Clinical data \\
\hline Х & $\square$ Dual use research of concern \\
\hline
\end{tabular}

Methods

n/a Involved in the study

Х ChIP-seq

\ $\square$ Flow cytometry

$\bigotimes \square$ MRI-based neuroimaging 